\title{
Effect of Filler and Binder Contents on Air Voids in Hot-Mix Asphalt for Road Pavement Construction
}

\author{
Isooba John, Mugume Rodgers Bangi, Muhwezi Lawrence \\ Civil and Building Engineering Department, Faculty of Engineering, Kyambogo University, Kampala, Uganda \\ Email: jbisooba@gmail.com,mugume_2rb@yahoo.co.uk,1muhwezi@hotmail.con
}

How to cite this paper: John, I., Bangi, M.R. and Lawrence, M. (2021) Effect of Filler and Binder Contents on Air Voids in Hot-Mix Asphalt for Road Pavement Construction. Open Journal of Civil Engineering, 11, 255-289.

https://doi.org/10.4236/ojce.2021.113016

Received: June 12, 2021

Accepted: July 27, 2021

Published: July 30, 2021

Copyright $\odot 2021$ by author(s) and Scientific Research Publishing Inc. This work is licensed under the Creative Commons Attribution International License (CC BY 4.0).

http://creativecommons.org/licenses/by/4.0/

\begin{abstract}
Filler and binder make up a small proportion of bituminous mixtures, hence they are considered as important ingredients of mixtures. Sometimes due to equipment error during production, some mixtures retain extra or a reduced amount of filler or binder as compared to the design mix formula. It is thought that the poor performance of bituminous mixtures is a result of inadequate proportioning of materials and the use of inappropriate compaction tools. This study was intended to appreciate the influence of contents of filler and binder in relation to durability in asphalt mixtures. Filler used was crushed stone passing $0.075 \mathrm{~mm}$ sieve, while the binder was $35 / 50$ penetration grade. Several trial mixes were prepared following Ugandan specifications for Road and Bridge Works, and the Asphalt Institute in MS-2. Marshall design method was used, studying volumetric properties with an average stability value of $22.3 \mathrm{kN}$, average flow value of $3.7 \mathrm{~mm}$, VA of $4.4 \%$, VFB of $69.3 \%$, and VMA of $14.2 \%$. Also, compaction of mixtures to assess its performance at optimum filler and binder contents was done. Compaction was done using an Automatic Impact Hammer, a Vibrating Hammer, and a Superpave Gyratory compactor aimed at simulating secondary compaction by traffic and assessing the retained air voids which was 3.3\%, 1.3\%, and $0.7 \%$ respectively. Generally, in bituminous mixtures when a vibrating hammer or a gyratory compactor is recommended for compaction, coarser mixes would be the best choice.
\end{abstract}

\section{Keywords}

Aggregate Gradation, Dense Bituminous Macadam, Marshall Properties

\section{Introduction}

Dense bituminous macadam $(\mathrm{DBM})$ is a binder course used for roads with a 
greater number of heavy commercial vehicles and a close-graded premix material. Ganapati and Adiseshu [1] defined Dense Bituminous Macadam (DBM) mixes as mixtures consisting of bitumen as an adhesive to bind the mineral aggregate which provides strength and toughness to the mix. Garcia and Hansen [2] described dense-graded hot-mix asphalt as a bituminous construction material that can be used effectively in all pavement layers for all traffic conditions. DBM as a mixture of coarse aggregate, fine aggregate, and asphalt binder, mixed, placed and compacted at elevated temperatures basing on the binder type [3].

The performance of any DBM mixture is achieved by careful aggregates selection [4]. Some aggregates used in DBM mix design have some porosity which tends to absorb bitumen into the pore structure and the absorbed bitumen is not considered as a binder in the asphalt mixtures [5]. The right proportioning of aggregates to be used for DBM production is a key factor in achieving a good workable mix [6]. Also, Deepesh and Yadav [7] noted that variations in the aggregate gradation within the limits specified can affect the DBM mix design properties.

Bitumen bonds the particulate mineral aggregates together to form a cohesive mass at working temperature between $150^{\circ} \mathrm{C}$ and $190^{\circ} \mathrm{C}$ [8]. Ray [9] noted that the amount of binder and filler contents are the two components that most affect air voids in the asphalt mix. Diab and Enieb [10] in their study found out that the blend of mineral filler and asphalt binder forms the asphalt mastic which plays a major role in controlling the mechanical behaviour of the mixture. Zaynab [11] also added that filler is the major contributor to the failure process in asphalt properties and it has a great effect on the hot-mix asphalt properties. In their research work, they remarked that asphalt pavement layers consist of mineral filler, coarse and fine aggregates, all bonded together by the asphalt binder and blended at pre-specified weight proportions determined from the mix design.

Insufficient air voids (air voids less than 3\%) resulting from binder content being higher than the optimum is one of the common causes of bleeding in asphalt mixtures [12]. Hot Mix Asphalt mixes should have sufficient binder content for durability and enough air voids under increased densification for better stability of the mixes. Therefore, at the design stage, it is essential to ensure that these two components are closely controlled.

AASHTO T 166 [13] in relating compaction effort and percent air voids in the compacted specimens confirmed that the test is performed using the Saturated Surface Dry (SSD) procedure. Moreover, the efficiency of compaction in the process of reducing air voids at a given mix was found to be a function of the filler and binder content with respect to the compaction tool used. The Asphalt Institute in MS-2 [14] showed that the selection of proper compaction level during the mix design phase is critical for proper mix performance.

\subsection{Statement of the Problem}

In general, there is an increasing number of axles, wheel loads and traffic on 
road pavements in Uganda today. It is expected that this situation will continue as long as there is a continued expansion of the road network. This is a challenge to asphalt experts to make decisions on what type of a mix can resist such pavement loading and tire pressures. Also, there is a need for improvement in the choice of laboratory compaction equipment that can appropriately simulate field conditions on secondary compaction. An asphalt mixture is a combination of materials, small alterations in the contents of filler and binder yield diverse engineering properties. Therefore, the purpose of this study was to appreciate how small changes in the contents of filler and binder can affect DBM mixtures since it can be used as base course, binder course, and as well wearing course.

The conceptual framework in Figure 1 gives an insight into the study, plan and interconnectivity of all the conceptual variables. Filler and binder in DBM mixtures formed the independent variables. Optimizing the DBM mixture involved aggregates (coarse and fine), filler, and binder, by means of the Marshall mix design method. This process was influenced by intervening factors such as compaction levels and test standards. The dependent variables were the mix properties, which were compared with the DBM mixture parameters in [15] and the performance indicators.

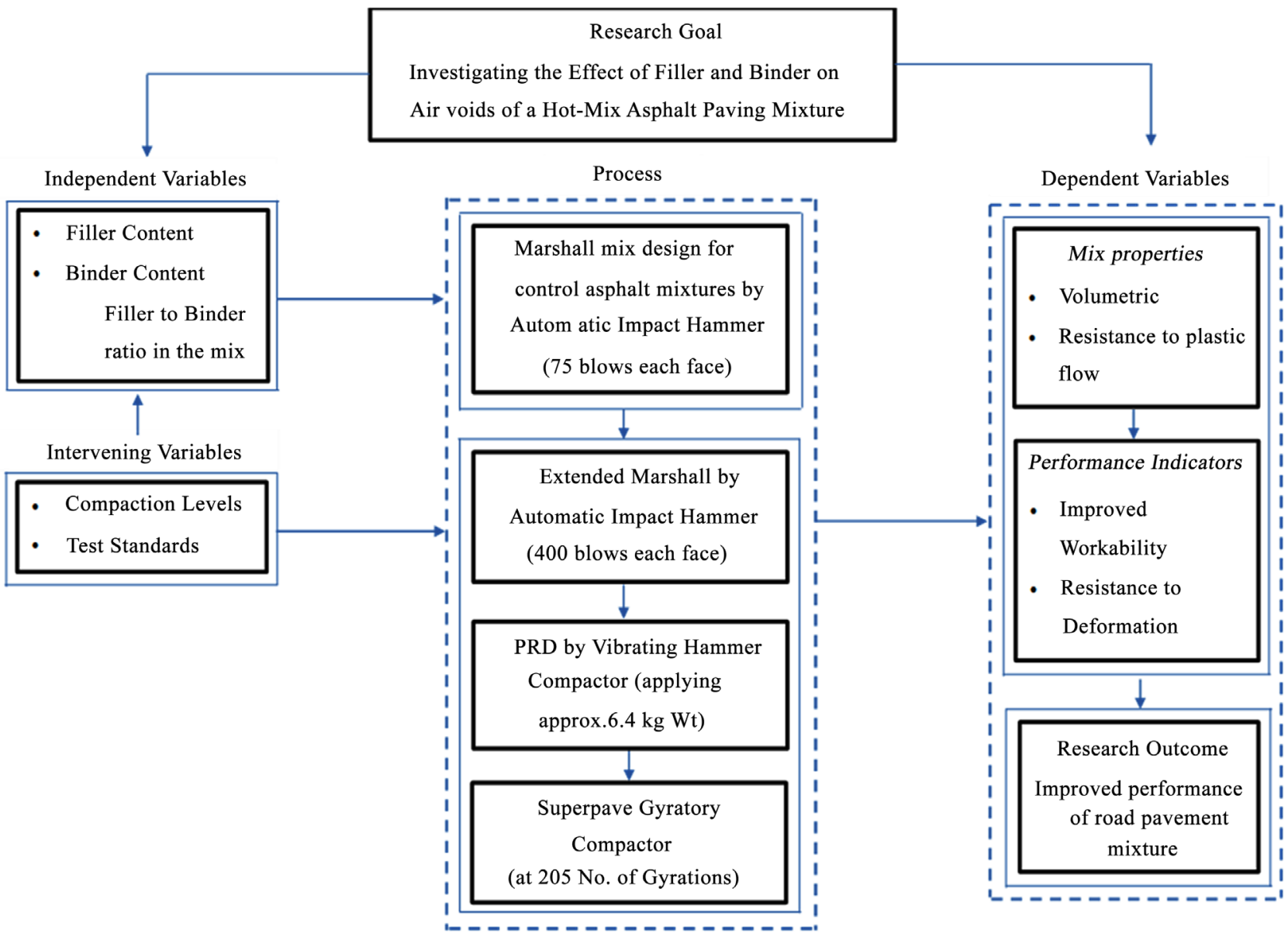

Figure 1. Conceptual framework of the research. 


\subsection{Main Objective}

The primary objective of this study was to assess the effect of filler and binder contents on volumetric properties which relate to durability. An additional aspect of this study was to assess the impact of compaction methods on air voids content.

\subsubsection{Specific Objectives}

The specific objectives of this research were:

1) To identify an appropriate DBM sensitive mixture to recognize the Marshall design method to obtain optimum filler and binder contents.

2) To design DBM mixtures with small range alterations in contents of filler and binder from the job mix formula (optimum).

3) To evaluate the refusal density laboratory compaction test methods to simulate realistic field compaction levels and performance characteristics.

\subsubsection{Research Questions}

1) What effect is caused by altering contents of either filler or binder on air voids in a DBM mixture for pavement layer construction?

2) When does the DBM mixture become tender and difficult to compact when filler content is altered from the optimum binder content?

3) How will the DBM mixture behave when air voids requirement is not met at the design stage when all material properties comply?

\subsection{Research Justification}

Filler and binder are the principal contributors to early pavement failures where its contents in the hot-mix asphalt have a significant effect on mixture performance. This research seeks for a more functional, performance-based mixture which also addresses cost and safety. Besides, other benefits in having good pavements like reduction in travel time over longer distances, minimizing cases of accidents, and reduction in vehicle repair costs can be related to choosing a mixture with better functional and performance. The research results can be used by the Ministry of Works and Transport (MoWT) of Uganda, to improve on the guidelines in regard to extended compaction as a way of minimizing air voids which is a function of the compaction tools and methods used in the laboratory to predict secondary compaction on pavements. Asphalt mixtures ought to be optimally proportioned for the paved mixture to last for the anticipated period of time with minimal maintenance. Even though proper workmanship and construction practices are perfectly exercised, poorly proportioned mixtures will fail prematurely.

Even though the study is put in the context of the construction variation effect and with the purpose of aiming to improve construction quality, the knowledge gained here can be utilized in the mix design process. Mix design engineers will be able to compare the predictive performance of various mixes, and make sure 
the best mix is chosen for the project. Other information from this study will aid in a better understanding of asphalt mix properties and the related laboratory test methods.

\subsection{Scope of the Study}

Testing procedures used in this study were chosen to analyze the effect of varying contents of filler and binder in a single aggregate gradation. The tests used in this study included; maximum specific gravity, bulk density, and Marshall stability and flow. Compaction methods included; Normal Marshall compaction by applying 75 blows on each face, Extended Marshall compaction using an automatic impact hummer, Extended Marshall compaction using a vibrating hummer, and Compaction using a Gyratory mechanism.

All tests in this study were prepared and performed in the laboratory. No specimens were taken from the field nor were any test performed in the field.

The selected aggregate gradation contained $20-28 \mathrm{~mm}, 14-20 \mathrm{~mm}, 6-14$ $\mathrm{mm}, 0.075-6 \mathrm{~mm}$, and passing $0.075 \mathrm{~mm}$ sizes, material passing $0.075 \mathrm{~mm}$ was used as filler. The aggregates and filler were sampled so that all sizes came from the same location in the quarry and thus thought to have the same properties.

A sample of bitumen manufactured by ENI-Italy refineries (Reffinaria di Livorno ENI-Italy) was used for all tests. Thus, every single precaution was taken to ensure that the test results focused on the effect of varying the contents of filler and binder only.

\section{Research Methodology}

The steps followed by this study, aimed at a sensitive optimized DBM mixture which acted as a basis to develop other mixtures. The steps were based on the mix design procedures described by the Marshall method in the [14]. Literature was reviewed and the information is available on how contents of filler and binder can affect asphalt mixtures. Other parts of the research steps comprised material identification and sampling, evaluation of collected material and methods that could permit the accomplishment of the objectives of this study. The quality of materials and sample preparations were carried out using standard methods. The test results were graphically plotted to come up with the optimum binder content. All test results were measured against the standard limits provided by the MoWT General Specifications for Road and Bridge Works of Uganda.

This research followed an experimental approach as the main method of obtaining data, and also considered some secondary data for backing up the information. Emphasis was placed on performing tests as a method of collecting numerical data, the summary of those data and the drawing of inferences from the data by comparing it with the specification requirements. 


\subsection{Materials}

\subsubsection{Aggregates}

Quarried rock was processed to make it suitable for use in asphalt production. Large stone boulders were crushed resulting in fractured particle faces. The crushed stone was sized by screening, and the dust resulting from the crushing was removed by washing. Aggregates were placed close to the stockpiles for visual assessment to confirm if there was no mixing of different sizes during conveyance. Aggregate sizes 28 to $20 \mathrm{~mm}, 20$ to $14 \mathrm{~mm}, 14$ to $6 \mathrm{~mm}$, and 6 to 0.075 $\mathrm{mm}$ were sampled from hot-bins as shown in Figure 2. For subsequent laboratory testing, quartering of the sampled aggregate material was carried out following the standard test procedure [16].
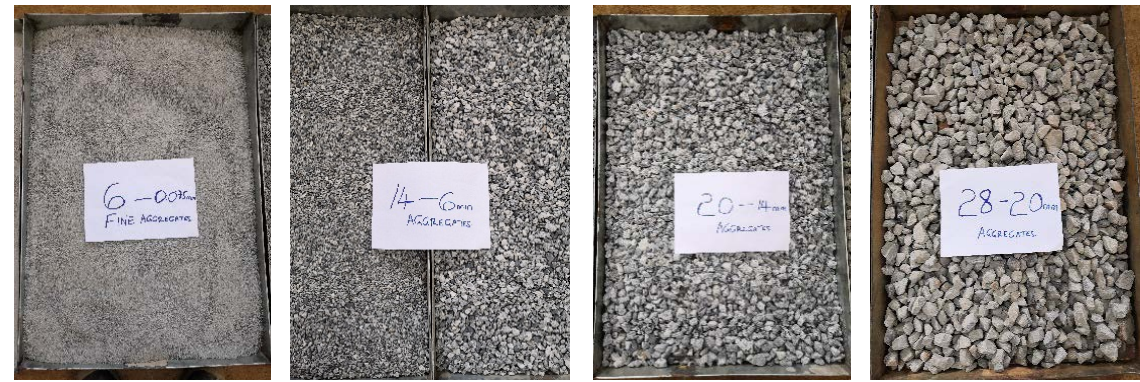

Figure 2. Different aggregate sizes.

\subsubsection{Mineral Filler}

Finer material is commonly known as mineral filler from the crushing of stones, typically the material passing $0.075 \mathrm{~mm}$ sieve was sampled. Filler was added to the aggregate blend to meet the target gradation curve. The source of filler material was the same where aggregates were sampled. A filler material is a collection of dust during the crushing of aggregates to appropriate sizes (Figure 3). The function of filler in asphalt mixtures is to fill the voids in the sand to make the total voids as small as possible as determined by the gradation of the sand. An approximate quantity of $50 \mathrm{~kg}$ was collected and used in the research after being subjected to tests.

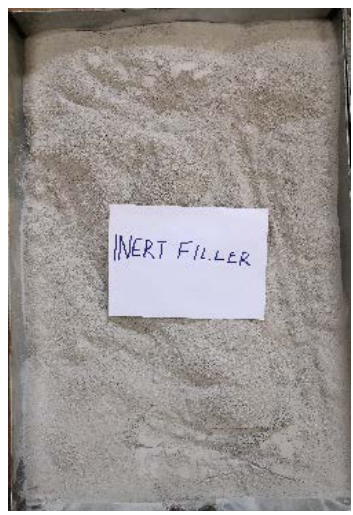

Figure 3. Mineral filler. 


\subsubsection{Bitumen Binder}

The bitumen binder, 35/50 penetration grade was used as a binding agent to glue aggregates into a coherent mass. Bitumen penetration grade 35/50 was used because it is adequately stiff and performs well in asphalt mixtures under moderate temperature and for all traffic loading conditions [15]. Solid asphalt binder was sampled by cutting it from the storage tank and placed into good-sized tins as shown in Figure 4. An approximate quantity of 4 kilograms was sampled from each container and tested after mixing.

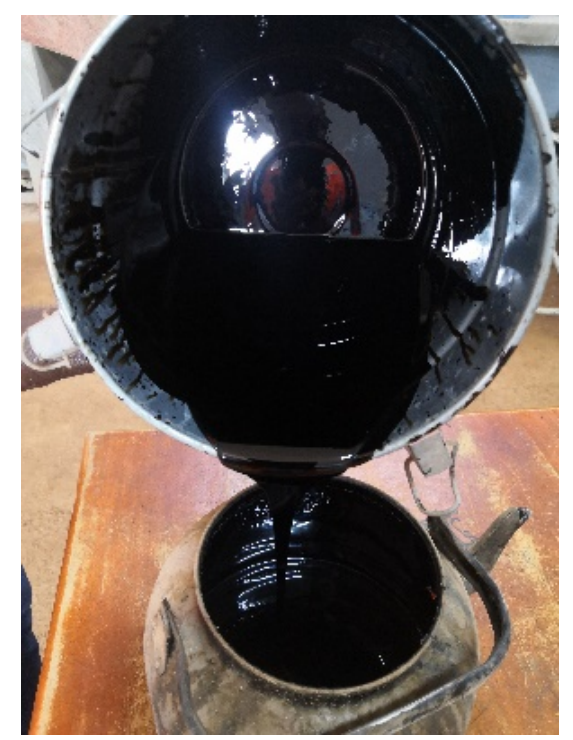

Figure 4. Bitumen sample.

\subsection{Methods}

\subsubsection{Aggregate Properties}

Aggregates are recommended for testing and their physical properties are categorized into consensus and source properties as highlighted by the [14]. The gradation property was determined using wet sieving for both individual and blended aggregates. Gradation of aggregates was done using the following BS sieve sizes; $37.5 \mathrm{~mm}, 28.0 \mathrm{~mm}, 20.0 \mathrm{~mm}, 14.0 \mathrm{~mm}, 10.0 \mathrm{~mm}, 5.00 \mathrm{~mm}, 2.00 \mathrm{~mm}$, $1.18 \mathrm{~mm}, 0.425 \mathrm{~mm}, 0.300 \mathrm{~mm}$, and $0.075 \mathrm{~mm}$. Aggregates were also tested for strength, toughness, hardness, shape, clay content, specific gravity and water absorption properties. To ensure good internal friction, the aggregate was tested for shape. The limiting flatness of aggregate reduces the chances of particle breakage and sliding under load and limiting the clay content enhances the bonding between bitumen and aggregate particles.

\subsubsection{Filler Properties}

In the current study, inert material in form of dust extracted from other aggregate material sizes during processing was used as mineral filler. The mineral filler material used in DBM mixtures was evaluated in terms of density, gradation and plasticity index following standard test procedures. 


\subsubsection{Asphalt Binder Properties}

Asphalt binders are most commonly characterized by their physical properties. This is because an asphalt binder's physical properties directly describe how it will perform as a constituent in hot-mix asphalt pavement. An asphalt binder (35/50 penetration grade) obtained from the one source, was used as the binder to prepare all the DBM mixtures for this research. Different quality tests i.e. penetration, softening point, flush and fire point, specific gravity, viscosity, solubility, and mass change were carried out on asphalt binder during this study to assess its basic physical properties through various laboratory steps.

\subsubsection{Specific Gravity of Total Aggregates}

The specific gravity of aggregates is needed to determine the weight-to-volume relationships and to calculate the many volume-related quantities such as VMA and VFB in the asphalt mixture. The lower specific gravity of aggregates indicates that there is a relatively high volume of aggregates at a similar weight as compared to aggregate of higher specific gravity. Thus, higher volume aggregate needs higher volume bitumen to coat all the aggregate particles [17].

Absorption is used as an indicator of the aggregate durability and how much bitumen is most likely to be absorbed [18]. The absorptiveness of the aggregates used in the asphalt mixture is critical in determining the optimum binder content. Effective binder content is the volume of binder not absorbed by the aggregate. It is calculated based on the aggregate bulk specific gravity (Gsb) and the aggregate effective specific gravity (Gse).

The theoretical specific gravity $G$ is the specific gravity without considering air voids, and is given by:

$$
G=\left(P_{1}+P_{2}+\cdots+P_{n}\right) /\left[\left(P_{1} / G_{1}\right)+\left(P_{2} / G_{2}\right)+\cdots+\left(P_{n} / G_{n}\right)\right]
$$

where,

$$
\begin{aligned}
& G=\text { Average specific gravity; } \\
& G_{1}, G_{2}, \cdots, G_{n}=\text { Specific gravity values for fraction } 1,2, \cdots, n ; \text { and } \\
& P_{1}, P_{2}, \cdots, P_{n}=\text { Weight percentages of fraction } 1,2, \cdots, n .
\end{aligned}
$$

\subsection{Marshall Mix Design}

The aim of generating the mix design was to determine the optimum blend of materials using a single selected aggregate gradation. The characteristics of aggregates, filler, bitumen and the air voids content of the compacted DBM mixture determine the physical properties of the mixture. Determining the optimum bitumen content $(\mathrm{OBC})$, variations of bulk density, Marshall stability, flow values and voids in the compacted mix against bitumen contents graphs were plotted. The binder content corresponding to 4.0 percent air voids was selected as the OBC. The OBC was used to prepare a working mix which was compacted and verified for conformity with the DBM requirements of the MoWT Specification of Uganda. Preparation of samples followed the Marshall method and afterwards volumetric and resistance to plastic flow was determined using stan- 
dard procedures and tools.

\section{Sample Preparation}

A mix design was performed using the Marshall method by preparing and compacting samples based on 0.5 percent increments of bitumen, with two bitumen contents below and two above the expected bitumen content. This was done in accordance with [19] Test Methods for Resistance to Plastic Flow of Bituminous Mixtures Using Marshall Apparatus. The [14], stated that basing a mix design on a single trial bitumen percentage would allow no check on the reliability of the test results. For that reason, 3.5, 4.0, 4.5, 5.0, and 5.5 percent bitumen contents by the dry weight of combined aggregates were used. The ultimate aim of considering a range of bitumen contents was to prepare batches that bracket the anticipated optimum binder content. Approximately $1200 \mathrm{~g}$ of aggregates and filler put together was measured, placed in an oven set at a temperature of $165^{\circ} \mathrm{C}$ for approximately four hours.

The specimens were compacted using a machine with a hummer tamping face diameter of $98.5 \mathrm{~mm}$, utilizing free falling weight of $4536 \pm 9 \mathrm{~g}$, at a drop height of $457 \pm 3 \mathrm{~mm}$, with a dropping frequency of $55 \pm 5$ (blows/min.) giving 75 blows on each face at a temperature of $155^{\circ} \mathrm{C}$. Three duplicate samples were prepared for each bitumen content and the average value was considered if no big difference was observed in the test result.

\subsection{Deviated DBM Mixtures}

In this study, the behaviour of DBM mixtures was studied with small alterations in filler and binder contents. Filler was added in increments of 0.4 percent i.e. $5.3,5.7,6.1$, and 6.5 percent, while binder was added in increments of 0.15 percent i.e. 4.2, 4.35, 4.5, 4.65, and 4.8 percent.

Since the aim of this study was to appreciate the influence of filler and binder on the engineering properties, the following were investigated; Marshall Tests, Stability, Flow, Percent of Air Voids (VA), Voids in Mineral Aggregate (VMA), and Percent Voids Filled with Bitumen (VFB).

The study also aimed at checking the following to confirm the applicability in comparison to the MoWT Specification requirements and the selection was based on three criteria:

1) The selection must fall within the recommended range of filler to binder ratio (0.8 - 1.6 by mass), and should not have a big impact on coarse graded asphalt mixtures [14],

2) The variation of bitumen content from the optimum at construction by \pm 0.3 percent, should not have an impact on the asphalt mixtures [15],

3) The gradation of the overall aggregate blend must be within the specified limits given in Table 4202/6 [15].

To reasonably address the possible variation of mixture mechanistic properties with respect to the variation of filler content, the aggregate compositions 
were kept the same but the amount of mineral filler was changed. To do so, an average gradation which conformed with the gradation envelope was selected. The combined aggregate gradation for both coarse and fine was maintained for all DBM mixtures, only contents of filler and binder were altered.

Also due to equipment error, sometimes more bitumen is released at the mixing stage hence lead to a significantly high value. As well bitumen might not get into the mix due to blockage of nozzles and/or sticking to the walls during mixing this may lead to a significantly low value. Sometimes the aggregates $0 / 6 \mathrm{~mm}$ might have more fine material finer than $0.075 \mathrm{~mm}$ during batching, this significantly increases the filler content in the asphalt mixtures. The last observation is dust coatings on coarse aggregate which can accumulate and increase on filler content in the asphalt mixtures. The DBM mixtures were checked for their performance using the test standards indicated in Table 1.

Table 1. Performance tests used to investigate DBM mixtures.

\begin{tabular}{ccr}
\hline Asphalt Type & Test Description & International Standard \\
\hline Volumetric Properties & AASHTO T-245: 2020 \\
DBM 30 & Resistance to Plastic Flow & AASHTO T-245: 2020 \\
& Percentage Refusal Density (PRD) & TRL Overseas Road Note 31
\end{tabular}

\subsubsection{Experimental Design and Testing Matrix}

In the experimental design, four sets of samples were prepared with equal aggregate weights (coarse and fine), but with varying filler content in increments of 0.4 percent starting with 5.3 percent. Each set had five design matrices prepared using similar filler content in the mix, but with varying bitumen content in increments of 0.15 percent starting with 4.2 percent. In the whole arrangement, 20 different mixtures were developed and considered in this research as shown in Table 2.

Table 2. Experimental design and testing matrix.

\begin{tabular}{rccccc}
\hline \multicolumn{5}{c}{ RANGE OF FILLER-TO-BINDER RATIO } \\
\hline \multirow{2}{*}{ Percent } & & \multicolumn{4}{c}{ Filler Content } \\
& & 5.3 & 5.7 & 6.1 & 6.5 \\
& 4.2 & 1.26 & 1.36 & 1.45 & 1.55 \\
Binder Content & 4.35 & 1.22 & 1.31 & 1.40 & 1.49 \\
& 4.5 & 1.18 & 1.27 & 1.36 & 1.44 \\
& 4.65 & 1.14 & 1.23 & 1.31 & 1.40 \\
& 4.8 & 1.10 & 1.19 & 1.27 & 1.35 \\
\hline
\end{tabular}

\subsubsection{Sample Fabrication}

For a one design matrix, a total of $20.1 \mathrm{~kg}$ of a dry aggregate blend comprising of $20 / 28 \mathrm{~mm}, 14 / 20 \mathrm{~mm}, 6 / 14 \mathrm{~mm}$ and $0 / 6 \mathrm{~mm}$ sizes was weighed and placed in a 
mixing bowl. Mineral filler was also weighed and added into the dry aggregates blend. The bowl containing dry aggregates and filler was placed in an oven set at a temperature of $165^{\circ} \mathrm{C}$ for a minimum of four hours.

A portion of penetration grade bitumen $35 / 50$, just enough for a one-time mixing was placed in another oven set at $165^{\circ} \mathrm{C}$ for about two hours. Bitumen after two hours in the oven could easily flow and coat the hot blended aggregate.

The hot aggregates and filler together at a constant weight and temperature were removed and placed on an electronic weighing scale. A crater was formed in the hot aggregate material to contain bitumen and to eliminate bitumen from sticking to the walls of the bowl. Specifically, an intended amount of bitumen at $165^{\circ} \mathrm{C}$ was added directly into the hot blended aggregate material by weight using an electronic scale readable to $0.1 \mathrm{~g}$.

The bowl containing hot aggregates, filler and bitumen was removed from the weighing scale and placed on a circular stand where mixing started. Under the mixing bowl, a gas cylinder mounted with a burner was positioned for producing regulated fire. The fire was placed to maintain the mixing temperature required of about $160^{\circ} \mathrm{C}$.

Manual mixing of materials started and the process continued until all aggregates were uniformly coated with bitumen. After mixing exhaustively in the shortest time possible, the bowl containing the bituminous mixture was removed from the mixing stand. The mixture was immediately transferred into the riffle box of $50 \mathrm{~mm}$ slot to homogenously reduce to smaller masses just enough for specific test specimens.

Two parallel specimens and each weighing approximately $2500 \mathrm{~g}$ were riffled for the Maximum theoretical density ( $\mathrm{Gmm}$ ) test. Three parallel specimens and each weighing approximately $1200 \mathrm{~g}$ were prepared for $102 \mathrm{~mm}$ diameter mould for the Marshall test (75 blows each face). Three parallel specimens and each weighing approximately $1205 \mathrm{~g}$ were prepared for $102 \mathrm{~mm}$ diameter moulds for extended Marshall test using an automatic impact hummer (400 blows each face). Three parallel specimens and each weighing approximately $4196 \mathrm{~g}$ were prepared for the PRD test using an electrically operated vibrating hummer (15 \pm 2 minutes each face), and three parallel specimens and each weighing approximately $4700 \mathrm{~g}$ were prepared for Superpave gyratory compaction test using 205 gyrations.

After placing the required quantity of DBM mixture into the respective moulds, the moulds plus the DBM mixture were placed back in the oven set at a temperature of $160^{\circ} \mathrm{C}$ for about two hours for mixture conditioning. Afterwards, moulds containing the DBM mixture were removed one after the other and compacted as required.

\subsection{Compaction to Refusal Density}

The second part of this study was to evaluate the different compaction efforts in predicting the mixture's behaviour after field secondary compaction by traffic. 
DBM mixtures were subjected to extended compaction effort, whereby compaction was continued until no further densification of specimens was obtained. The objective of compaction to refusal density is to design asphalt mixtures that can retain the minimum air voids content requirement. Three compaction efforts using different tools and methods were applied and specimens were analyzed for retained air voids: 1) Automatic Marshall Impact Hummer, 2) Electrically Operated Vibrating Hummer and 3) Gyratory Compactor

\subsection{Validity and Reliability of Results}

Validity and reliability are concepts used to evaluate how well a method measures the quality of research. To ensure repeatability and reproducibility of results recorded in the laboratory for the tests carried out, the following measures were employed during testing:

1) Regular presence of the researcher during testing;

2) Use of skilled technicians;

3) Use of calibrated laboratory equipment;

4) Critical observation of all standard test procedures used (BS, ASTM, and AASHTO);

5) Use of precise weighing scales;

6) Processing temperature during mixing was monitored and regulated using thermometers and;

7) Three trial samples for each test determined were used to average each property value.

\subsection{Data Analysis}

Analysis of data for independent variables was done in order to identify which factor significantly contributed to the dependent variables. The independent variables analyzed included filler and binder dosages. All test data were analyzed using Excel-based program and, some data were analyzed using a statistical regression method. The objective was to investigate the effect of filler and binder on air voids in DBM mixtures basing on conformity to the engineering requirements.

\section{Discussion and Analysis of Results}

\subsection{Material Characterization}

\subsubsection{Aggregate Properties}

Since aggregate properties play a big role in overcoming permanent deformation, asphalt mixtures constitute approximately 95 percent of aggregates [14] \& [18]. The physical properties of aggregate materials were tested to check the aggregate suitability for bituminous mixtures and test results are shown in Table 3 and Table 4. The analysis of the aggregate sizes and gradation results were based on DBM bituminous material specifications. Also, since the gradation of individual aggregate sizes could not fall within the DBM gradation specified limits, 
blending of different aggregate size fractions to obtain the desired continuous dense-graded type was done. Gradation of combined aggregate materials for bituminous mixtures is aimed to pass in the middle of the upper and lower limits shown in Figure 5. The gradation for the combined aggregate conformed with the gradation specified limits for DBM following MoWT General Specification for Road and Bridge Works of Uganda.

Table 3. Physical properties of coarse aggregates.

\begin{tabular}{|c|c|c|c|c|}
\hline No. & Laboratory Test & Designation & $\begin{array}{c}\text { Test } \\
\text { Results }\end{array}$ & $\begin{array}{c}\text { Specification } \\
\text { Limits }\end{array}$ \\
\hline 1 & Bulk specific gravity (oven-dry basis) & BS 812: Part 2: 1995 & 2.627 & Not Specified \\
\hline 4 & Water absorption, \% & BS 812: Part 2: 1995 & 0.29 & Max. 2 \\
\hline 5 & Los Angeles abrasion, $\%$ & ASTM C 131: 2014 & 20.6 & Max.50 \\
\hline 6 & Soundness loss by SSS, \% & ASTM C 88: 2017 & 0.06 & Max.12 \\
\hline 7 & Flakiness Index, \% & BS 812: Part 105.1: 1989 & 15.1 & Max.25 \\
\hline 8 & Ratio of $\mathrm{TFV}_{\text {soaked }} \& \mathrm{TFV}_{\mathrm{dry}}(\%)$ & BS 812: Part 111: 1990 & 92.7 & Min.75 \\
\hline 9 & Aggregate Crushing Value, \% & BS 812: Part 110: 1990 & 23.4 & Not Specified \\
\hline 10 & Aggregate Impact Value, \% & BS 812: Part 112: 1990 & 14.3 & Max. 35 \\
\hline 11 & Coating and Stripping Test, $\%$ & AASHTO T 182: 2002 & 98 & Min. 95 \\
\hline
\end{tabular}

Table 4. Physical properties of fine aggregates.

\begin{tabular}{ccccc}
\hline No. & Laboratory Test & Standards & Results & $\begin{array}{c}\text { Specification } \\
\text { Limits }\end{array}$ \\
\hline 1 & Bulk specific gravity (oven-dry basis) & BS 812: Part 2: 1995 & 2.61 & Not Specified \\
4 & Water absorption, \% & BS 812: Part 2: 1995 & 0.47 & Max. 2 \\
5 & Plasticity Index, \% & BS: 1377: Part 2: 1990 & Non-Plastic & Non-Plastic \\
6 & Sand equivalent, \% & AASHTO T176: 2017 & 88 & Min.50 \\
\hline
\end{tabular}

\subsubsection{Mineral Filler Properties}

The non-plastic material passing sieve $0.075 \mathrm{~mm}$ from sieving of aggregate is called a mineral filler. ASTM D 242 specification requires that filler passes through $1.18 \mathrm{~mm}, 0.600 \mathrm{~mm}, 0.300 \mathrm{~mm}$, and $0.075 \mathrm{~mm}$ sieves with the requirements of $100 \%, 97 \%-100 \%, 95 \%-100 \%$, and $70 \%-100 \%$ passing, respectively [20]. In this research the crushed rock dust was used as mineral filler which consisted of finely mineral matter of crusher fines. At the time of use, filler was sufficiently dry to flow freely and free from agglomerations. The mineral filler used conformed with the MoWT General Specifications for Roads and Bridge Works of Uganda as shown in Table 5.

Table 5. Physical properties of mineral filler.

\begin{tabular}{ccccc}
\hline No. & Laboratory Test & Standards & Results & $\begin{array}{c}\text { Specification } \\
\text { Limits }\end{array}$ \\
\hline 1 & Bulk Specific gravity & BS 812-2:1995 & 2.606 & Not Specified \\
2 & Percent Passing 0.075 mm Sieve & BS 1377-4:1990 & 82.9 & Min. 70\% \\
3 & Plasticity Index, \% & BS 1377-2:1990 & Non-Plastic & Max. 4 \\
\hline
\end{tabular}




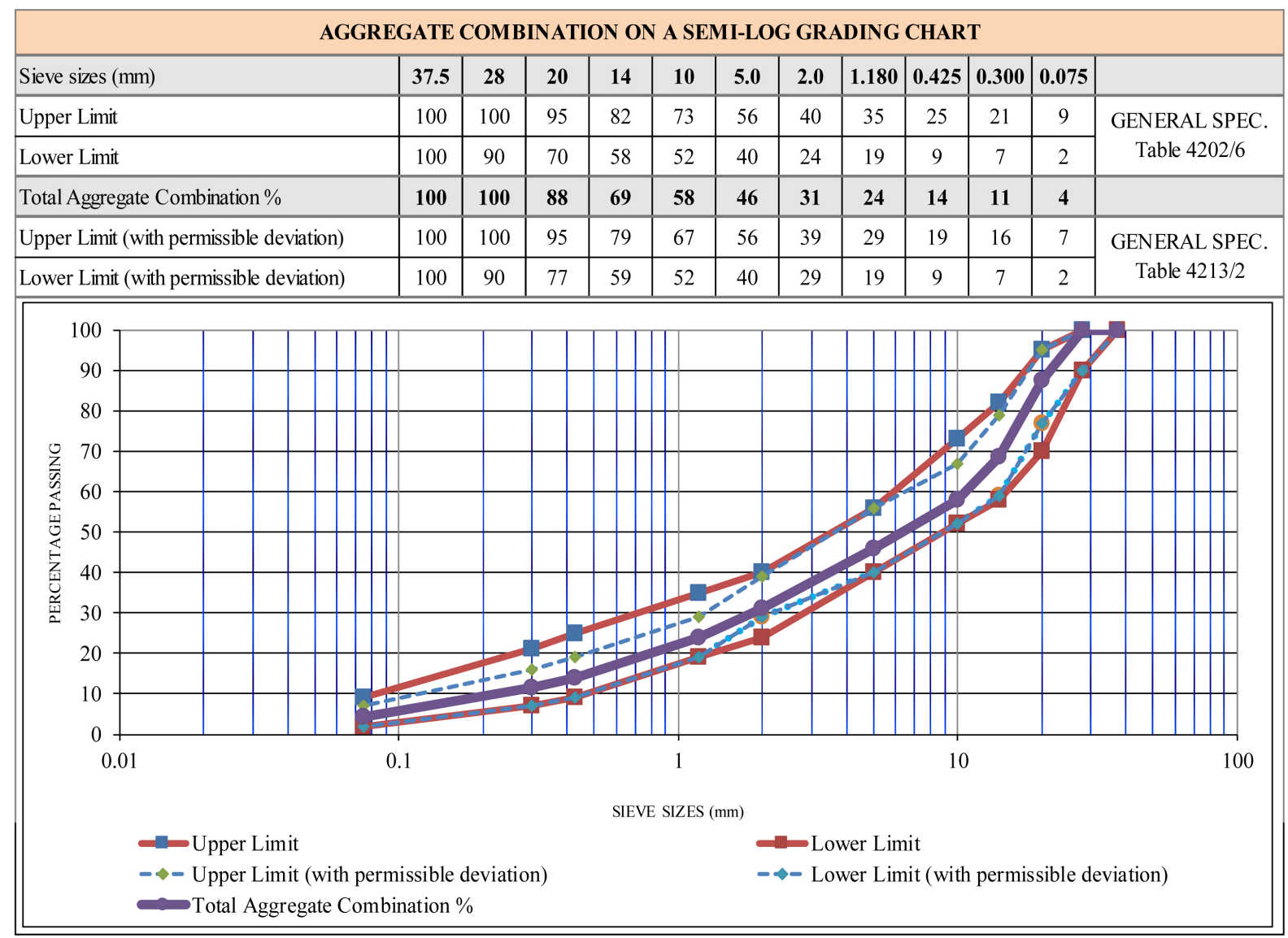

Figure 5. Final aggregate gradation with permissible limits.

\subsubsection{Bitumen Properties}

The results of the paving grade bitumen $35 / 50$ used in this research are given in Figure 6 and Table 6. The MoWT general specifications specify the mixing temperature for the bitumen type $35 / 50$ ranging between $140^{\circ} \mathrm{C}-165^{\circ} \mathrm{C}$. In addition, the Transport Research Laboratory specifies mixing temperature for paving grade bitumen $35 / 50$ ranging between $150^{\circ} \mathrm{C}-180^{\circ} \mathrm{C}$ [18]. While the manufacturer Eni refineries, recommended the appropriate temperatures for asphalt mixtures with $35 / 50$ paving grade bitumen to range between $160^{\circ} \mathrm{C}$ $180^{\circ} \mathrm{C}$ for mixing and $150^{\circ} \mathrm{C}-170^{\circ} \mathrm{C}$ for compacting. The research considered the manufacturer's recommendations for mixing and compaction temperatures since manufacturers monitored the bitumen behaviour for a long time. The viscosity determined at $135^{\circ} \mathrm{C}$ was $0.945 \mathrm{~Pa} \cdot \mathrm{s}$ as seen in Figure 6 . The density value of 1.028 of the bitumen (Table 6) was achieved which was later used for volumetric computations of the asphalt mixtures. The result generally complied with the MoWT, specification requirements and it was suitable for use in this study.

\subsubsection{Specific Gravity of Total Aggregates}

The combined bulk and apparent specific gravity values were used to calculate the effective specific gravity. This was achieved by using the attained average test values in Table 7 used in Equation (2.1). 
Table 6. Properties of bitumen.

\begin{tabular}{ccccc}
\hline No. & Laboratory Test & Standards & Results & Spec. Limits \\
\hline 1 & Penetration at $25^{\circ} \mathrm{C}, 100 \mathrm{~g}, 5 \mathrm{Sec} .(0.1 \mathrm{~mm})$ & AASHTO: T49-84 & 43.9 & $35-50$ max. \\
2 & Softening Point, $\left({ }^{\circ} \mathrm{C}\right)$ & AASHTO: T 53 & 50.6 & $50-58$ max. \\
3 & Flush and Fire Point, $\left({ }^{\circ} \mathrm{C}\right)$ & EN ISO 2592 & 250 & $\geq 240$ \\
4 & Specific Gravity & ASTM C $127-88$ & 1.028 & Not Specified \\
5 & Dynamic Viscosity $60^{\circ} \mathrm{C} \mathrm{mm} / \mathrm{s}$ & EN 12596 & 235 & $\geq 225$ \\
6 & Solubility, $\%(\mathrm{~m} / \mathrm{m})$ & PN-EN 12592 & 100 & $\geq 99$ \\
7 & Change of mass, $\%(\mathrm{~m} / \mathrm{m})$ & PN-EN 12607-1 & 0.1 & $\leq 0.5$ \\
\hline
\end{tabular}

Table 7. Aggregate specific gravities.

\begin{tabular}{|c|c|c|c|c|c|c|c|}
\hline \multicolumn{8}{|c|}{ AGGREGATE SPECIFIC GRAVITIES } \\
\hline \multicolumn{8}{|c|}{ Bulk Specific Gravity } \\
\hline Material Fractions & \multicolumn{2}{|c|}{ Trial 1} & \multicolumn{2}{|c|}{ Trial 2} & \multicolumn{2}{|c|}{ Trial 3} & Average \\
\hline $20-28 \mathrm{~mm}$ & 2.641 & 2.642 & 2.636 & 2.626 & 2.629 & 2.631 & 2.634 \\
\hline $14-20 \mathrm{~mm}$ & 2.624 & 2.626 & 2.624 & 2.625 & 2.624 & 2.626 & 2.625 \\
\hline $6-14 \mathrm{~mm}$ & 2.618 & 2.621 & 2.619 & 2.620 & 2.613 & 2.611 & 2.617 \\
\hline $0-6 \mathrm{~mm}$ & 2.618 & 2.611 & 2.614 & 2.613 & 2.604 & 2.602 & 2.610 \\
\hline Filler & 2.606 & 2.607 & & & & & 2.607 \\
\hline \multicolumn{8}{|c|}{ Apparent Specific Gravity } \\
\hline Material Fractions & \multicolumn{2}{|c|}{ Trial 1} & \multicolumn{2}{|c|}{ Trial 2} & \multicolumn{2}{|c|}{ Trial 3} & Average \\
\hline $20-28 \mathrm{~mm}$ & 2.662 & 2.657 & 2.653 & 2.648 & 2.647 & 2.649 & 2.653 \\
\hline $14-20 \mathrm{~mm}$ & 2.645 & 2.646 & 2.643 & 2.644 & 2.653 & 2.664 & 2.649 \\
\hline $6-14 \mathrm{~mm}$ & 2.640 & 2.648 & 2.640 & 2.641 & 2.635 & 2.633 & 2.640 \\
\hline $0-6 \mathrm{~mm}$ & 2.644 & 2.640 & 2.643 & 2.644 & 2.641 & 2.642 & 2.642 \\
\hline Filler & 2.62 & 2.62 & & & & & 2.620 \\
\hline
\end{tabular}

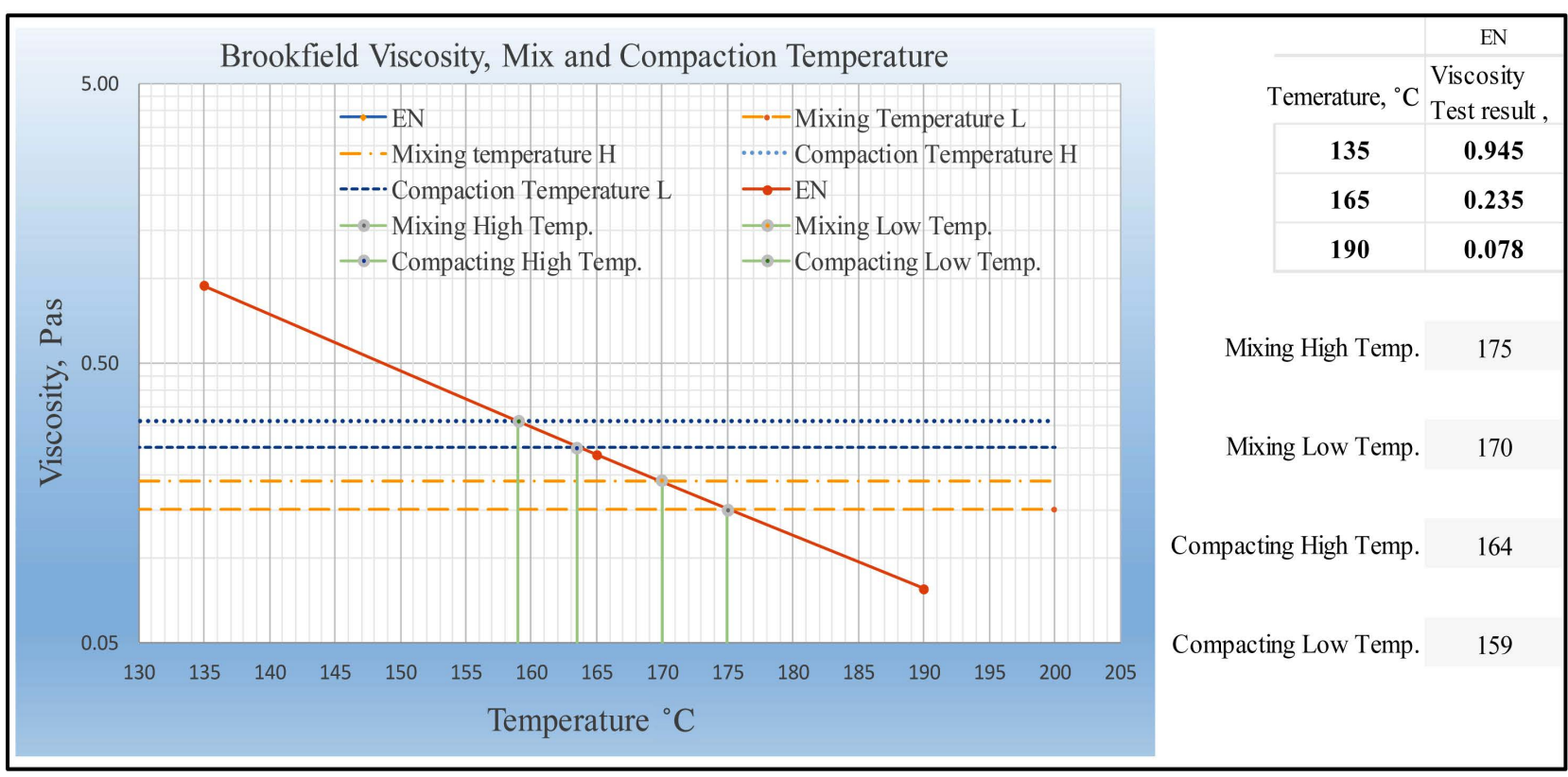

Figure 6. Temperature-viscosity for mixing and compaction. 
Bulk Specific Gravity

$$
=\frac{12+12+27+43+6}{\frac{12}{2.634}+\frac{12}{2.625}+\frac{27}{2.617}+\frac{43}{2.610}+\frac{6}{2.607}}=\frac{100}{38.221}=2.617
$$

Apparent Specific Gravity

$$
=\frac{12+12+27+43+6}{\frac{12}{2.653}+\frac{12}{2.649}+\frac{27}{2.640}+\frac{43}{2.642}+\frac{6}{2.620}}=\frac{100}{37.846}=2.642
$$

Effective Specific Gravity $=(2.617+2.642) / 2=2.629$

\subsection{Marshall Design Values}

The main aim was to identify an appropriate DBM sensitive mixture to recognize the Marshall design method to obtain optimum filler and binder contents and other engineering properties in compliance with specification requirements. Once the material physical properties met the MoWT specification requirements, the aggregate blend combination met the gradation requirements, the specific gravity of aggregates and bitumen determined, specimen preparations started. Following the two principle features of the Marshall method of mix design, measures such as density, air voids, voids filled with bitumen (VFB), and voids in mineral aggregate (VMA) were obtained from the test. As well the stability-flow test of the compacted specimens was performed. The values attained from testing the design mixture were plotted on graphs to choose the optimum binder content and the findings are presented in Table 8 read from Figure 7. Choosing the bitumen content at the mid-point of the percent air voids limits, which is 4.0 percent was considered [14]. Thus, the binder content recorded from Figure 7, was 4.5 percent by weight of the total mix. As well VFB (\%), VMA (\%), $\mathrm{G}_{\mathrm{mb}}(\mathrm{g} / \mathrm{cc})$, Stability $(\mathrm{N})$, and Flow $(\mathrm{mm})$ corresponding to 4.5 percent binder content were recorded from the matching graphs. The values were compared with the MoWT General Specification requirements shown in Table 9.

Table 8. Marshall design values.

\begin{tabular}{cccccccc}
\hline \multicolumn{7}{c}{ SUMMARY OF MARSHALL PROPERTIES (75 blows each face) } \\
\hline $\begin{array}{c}\text { Bitumen } \\
\text { Content, } \\
\mathrm{Pb}(\%)\end{array}$ & $\begin{array}{c}\mathrm{Gmb} \\
(\mathrm{g} / \mathrm{cc})\end{array}$ & $\begin{array}{c}\text { VMA } \\
(\%)\end{array}$ & $\begin{array}{c}\mathrm{Va} \\
(\%)\end{array}$ & $\begin{array}{c}\text { VFB } \\
(\%)\end{array}$ & $\begin{array}{c}\text { Stability } \\
(\mathrm{N})\end{array}$ & $\begin{array}{c}\text { Flow } \\
(\mathrm{mm})\end{array}$ & $\begin{array}{c}\text { Stability/Flow } \\
(\mathrm{N} / \mathrm{mm})\end{array}$ \\
\hline 3.5 & 2.299 & 15.2 & 5.7 & 62.6 & 9087 & 2.5 & 3634.8 \\
4.0 & 2.314 & 15.1 & 5.0 & 67.2 & 9842 & 3.1 & 3174.8 \\
4.5 & 2.321 & 15.3 & 4.1 & 73.4 & 11084 & 3.3 & 3358.8 \\
5.0 & 2.338 & 15.1 & 2.8 & 81.7 & 12487 & 3.5 & 3567.7 \\
5.5 & 2.366 & 14.5 & 1.4 & 90.1 & 12690 & 3.4 & 3732.4 \\
\hline
\end{tabular}


Table 9. Values from property plots against the specification.

\begin{tabular}{ccc} 
DESIGN REQUIREMENTS FOR DENSE BITUMEN MACADAM MARSHALL MIX DESIGN \\
\hline Property description & $\begin{array}{c}\text { Mixture } \\
\text { properties at 4 } \\
\text { percent air voids }\end{array}$ & $\begin{array}{c}\text { Specification Limits } \\
\text { (Table: 4203/4 Gen. Spec.), } \\
\text { (Table 8.5 Overseas Road Note 31) }\end{array}$ \\
\hline Binder Content, \% & 4.5 & $4.5 \%$ (for bidding purposes) \\
Marshall stability, N & 11,084 & Min. 9000 \\
Marshall flow, 0.25 mm & 3.4 & $2-4$ \\
Voids in mineral aggregate (VMA), \% & 15.3 & Min. 12.5 \\
Voids filled with bitumen (VFB), \% & 74.0 & $65-75$ \\
\hline
\end{tabular}
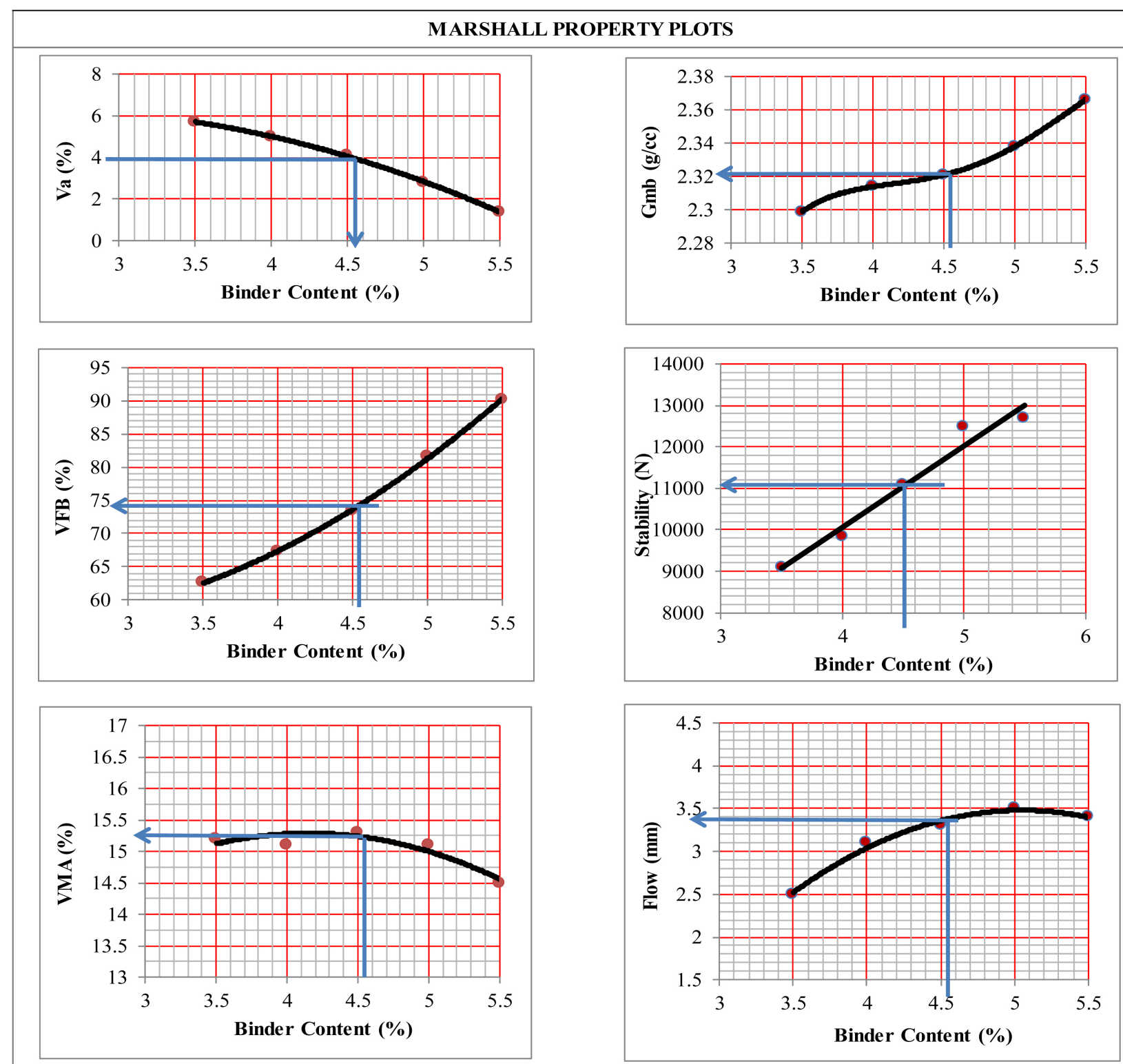

Figure 7. Influence of binder against Marshall properties. 


\subsection{Marshall Properties at Optimum Binder Content}

Deciding whether the DBM mix was satisfactory at the selected design binder content, a special mix was prepared at optimum binder content. The Marshall properties of the asphalt mixture prepared at optimum binder content (4.5 percent), and 95.5 percent total aggregates (coarse, fine and filler) in the mix is shown in Table 10. Marshall properties were determined and checked for conformity with the limits specified in the MoWT general specifications for roads and bridge works of Uganda. Since all measured values for the design mixture at 4.5 percent bitumen content met the design requirements, this was considered as the DBM sensitive control mixture for a subsequent research study.

Table 10. Mixture properties at optimum binder content.

\begin{tabular}{ccc}
\hline \multicolumn{2}{c}{ MARSHALL TEST RESULTS AT OPTIMUM BINDER CONTENT 4.5\% } \\
\hline Property description & $\begin{array}{c}\text { Mixture } \\
\text { properties } \\
\text { at optimum } \\
\text { binder content }\end{array}$ & $\begin{array}{c}\text { Specification Limits } \\
\text { (Table: 4203/4 Gen. Spec.), } \\
\text { (Table 8.5 Overseas Road Note 31) }\end{array}$ \\
\hline Marshall stability, N & 22,332 & Min. 9000 \\
Marshall flow, 0.25 mm & 3.7 & $2-4$ \\
Air Voids (Va), at 75 blows on each face, \% & 4.4 & $4-8$ \\
Voids in mineral aggregate (VMA), \% & 14.2 & Min. 12.5 \\
Voids filled with bitumen (VFB), \% & 69.3 & $65-75$ \\
\hline
\end{tabular}

\subsection{Design Mix Formula (DMF)}

The design mix formula provides the aggregate ingredients (coarse, fine and filler) to incorporate in the mix and the summation of all aggregate proportions add up to 95.5 percent as indicated in Table 11. Also, the inclusion of 4.5 percent bitumen amounts to 100 percent volume and mass required in the total bituminous mixture. Hence, the aggregate content (coarse, fine and filler) and the optimum binder content constituted the design mix formula as shown in Table 11. The aggregate proportions in the final mix were reduced using the equation below:

Table 11. Adopted design mix formula.

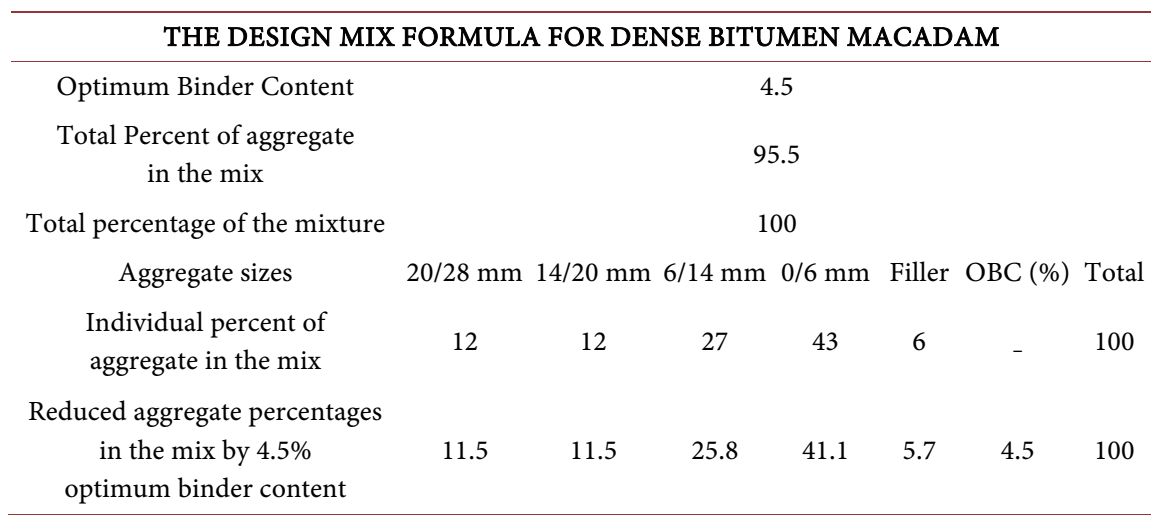




$$
\mathrm{RAP}=[(100-\mathrm{OBC}) / 100] * \mathrm{IAP}
$$

where; RAP is the Reduced Aggregate Proportion to be used in the final mix,

$\mathrm{OBC}$ is the Optimum Binder Content,

IAP is the Initial Aggregate Proportion used to determine the optimum binder content. Hence the application of Equation (3.1) shown above was as in Table 11 .

\subsection{Deviated DBM Mixes}

Mixtures prepared with filler and binder contents altered from the optimum contents as determined by Marshall mix design criteria were considered as deviated mixtures. The objective of designing DBM mixtures with small range alterations in contents of filler and binder from the job mix formula, was based on observations during production. Sometimes due to equipment error during production, some mixtures retain extra or a reduced amount of filler or binder as compared to the Design Mix Formula (DMF). The DMF for the DBM mixture was decided on after assessing the right quantities of materials in the mix. The DBM mixtures were subjected to a level of compaction related to traffic in terms of equivalent standard axles.

The results achieved from the Marshall mix design conducted, where the optimum filler content of 5.7 percent and optimum binder content of 4.5 percent by weight of total mix remained the basis to prepare altered DBM mixtures. The altered DBM mixtures were prepared by varying filler and binder contents from the DMF. Accordingly, both mechanical and volumetric analysis were conducted on specimens. Also, based on the principle that filler proportion in the coarse-graded mixes is characteristically allowed in the range from $0.8-1.6$ [14]. The filler proportion addresses the workability of asphalt mixtures. A low proportion in the mix results in a tender mix and is difficult to compact because it tends to move laterally under the compactor. A high proportion results in a stiff mix, but too much also result in a tender mix. Filler proportions indicated in Table 12, illustrates that the amount of filler in DBM mixtures have a demonstrative impact on the stability of the mixture, hence affect the performance.

Table 12. Marshall properties after 75 blows each face.

\begin{tabular}{cccccccccc}
\hline $\begin{array}{c}\text { Filler } \\
\text { Content }\end{array}$ & $\begin{array}{c}\text { Bitumen } \\
\text { Content } \\
\text { of mix, } \mathrm{Pb}\end{array}$ & $\begin{array}{c}\text { Dust to } \\
\text { Binder } \\
\text { ratio, } \\
\mathrm{P} 0.075 / \mathrm{Pb}\end{array}$ & $\begin{array}{c}\text { Maximum } \\
\text { SG, Gmm }\end{array}$ & $\begin{array}{c}\text { Bulk } \\
\text { Density of } \\
\text { compacted } \\
\text { mix, Gmb }\end{array}$ & VA & VMA & VFB & $\begin{array}{c}\text { Marshal } \\
\text { Stability }\end{array}$ & $\begin{array}{c}\text { Marshal } \\
\text { Flow }\end{array}$ \\
\hline$(\%)$ & $(\%)$ & & & $(\mathrm{g} / \mathrm{cc})$ & $(\%)$ & $(\%)$ & $(\%)$ & $(\mathrm{N})$ & $(\mathrm{mm})$ \\
\hline 5.3 & 4.2 & 1.26 & 2.504 & 2.252 & 10.0 & 17.5 & 42.6 & 18,870 & 4.7 \\
5.3 & 4.35 & 1.22 & 2.497 & 2.275 & 8.9 & 16.8 & 47.1 & 12,666 & 3.2 \\
5.3 & 4.5 & 1.18 & 2.478 & 2.279 & 8.0 & 16.8 & 52.3 & 13,569 & 4.0 \\
5.3 & 4.65 & 1.14 & 2.459 & 2.282 & 7.2 & 16.8 & 57.2 & 13,038 & 3.9 \\
\hline
\end{tabular}




\begin{tabular}{cccccccccc} 
Continued & & & & & & & & & \\
\hline 5.3 & 4.8 & 1.10 & 2.442 & 2.305 & 5.6 & 16.1 & 65.4 & 14,895 & 3.2 \\
5.7 & 4.2 & 1.36 & 2.496 & 2.338 & 6.3 & 14.4 & 56.0 & 24,556 & 4.8 \\
5.7 & 4.35 & 1.31 & 2.477 & 2.348 & 5.2 & 14.1 & 63.4 & 21,089 & 3.6 \\
5.7 & 4.5 & 1.27 & 2.462 & 2.350 & 4.6 & 14.2 & 67.9 & 21,262 & 3.7 \\
5.7 & 4.65 & 1.23 & 2.448 & 2.352 & 3.9 & 14.3 & 72.7 & 23,369 & 3.9 \\
5.7 & 4.8 & 1.19 & 2.438 & 2.365 & 3.0 & 13.9 & 78.6 & 23,224 & 3.4 \\
6.1 & 4.2 & 1.45 & 2.485 & 2.319 & 6.7 & 15.1 & 55.7 & 20,595 & 2.8 \\
6.1 & 4.35 & 1.40 & 2.475 & 2.341 & 5.4 & 14.4 & 62.2 & 21,103 & 3.3 \\
6.1 & 4.5 & 1.36 & 2.470 & 2.346 & 5.0 & 14.4 & 65.0 & 21,336 & 3.1 \\
6.1 & 4.65 & 1.31 & 2.460 & 2.347 & 4.6 & 14.4 & 68.2 & 15,094 & 2.3 \\
6.1 & 4.8 & 1.27 & 2.458 & 2.361 & 4.0 & 14.1 & 71.8 & 13,051 & 2.9 \\
6.5 & 4.2 & 1.56 & 2.474 & 2.369 & 4.2 & 13.2 & 68.1 & 16,570 & 3.5 \\
6.5 & 4.35 & 1.49 & 2.469 & 2.375 & 3.8 & 13.2 & 71.1 & 16,326 & 3.5 \\
6.5 & 4.5 & 1.44 & 2.459 & 2.374 & 3.4 & 13.3 & 74.2 & 21,249 & 3.2 \\
6.5 & 4.65 & 1.40 & 2.447 & 2.375 & 3.0 & 13.4 & 78.0 & 19,677 & 2.8 \\
6.5 & 4.8 & 1.35 & 2.444 & 2.374 & 2.9 & 13.6 & 79.0 & 14,686 & 3.3 \\
\hline & & & & & & & & & \\
\hline
\end{tabular}

The compaction effort of 75 blows on each side was used in preparing specimens with deviated contents of filler and binder. The specimens were used to determine the bulk density, air voids, voids in mineral aggregate, voids filled with bitumen, stability and flow. Table 12 illustrates the relationship between filler and binder contents altered from the optimum contents.

\subsubsection{Effect on Marshall Stability}

The principle of Marshall stability is the resistance to plastic flow of cylindrical specimens of a bituminous mixture loaded on the lateral surface. The stability values achieved following the standard specification [19] for Marshall compacted specimens at a standard test temperature of $60^{\circ} \mathrm{C}$, represents the strength of the mixture. Comparing the literature and the materials used in the research, Marshall stability values for all test samples were above the minimum 9000 Newton specified for DBM mixes following MoWT General Specifications for Road and Bridge Works of Uganda. It was observed that the filler-to-binder ratio of 1.36 (i.e. 5.7/4.2) attained the maximum stability of the DBM mixture shown in Figure 8. In this research, angular crushed aggregates were used together with a higher viscosity bitumen to prepare DBM mixtures. Generally, mixtures with 5.7 percent filler content were observed to have the highest stability values ranging between $21089 \mathrm{~N}$ to $24556 \mathrm{~N}$ as shown in Figure 8. This is because, in these mixes, maximum aggregate particle interlock and internal friction caused by gradation are expected more since it is the optimum filler content chosen. 


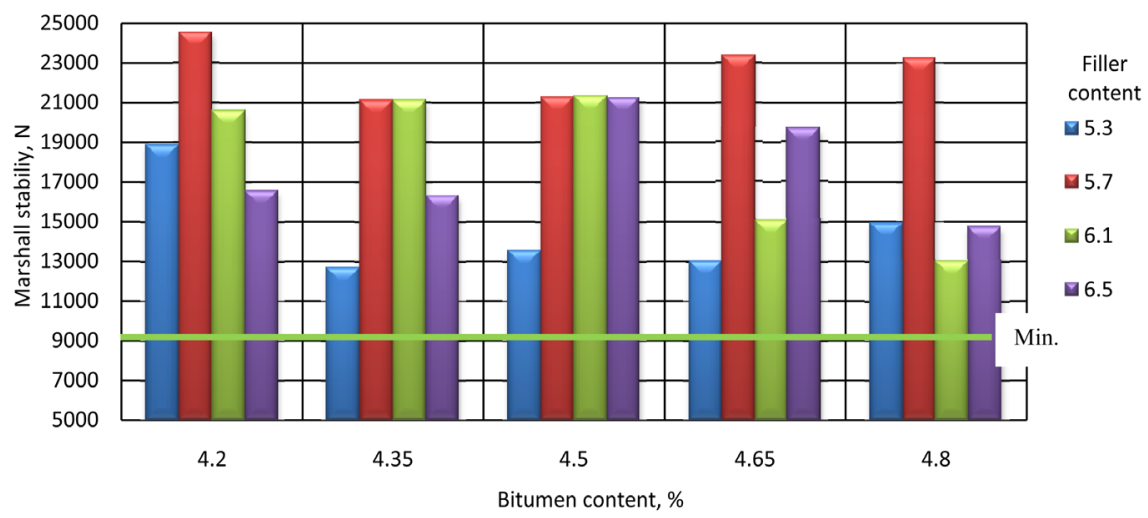

Figure 8. Variation of Marshall stability with bitumen contents.

\subsubsection{Effect on Marshall Flow}

Flow values are measured as vertical deformation of specimens in hundreds of inches from the start of loading up to the maximum load attained by the compacted specimen during testing at $60^{\circ} \mathrm{C}$. Flow values are obtained at the same time as the Marshall stability test is conducted. High flow values indicate a plastic mix that is more prone to permanent deformation, whereas low flow values may indicate a mix with higher voids and insufficient binder for durability and could result in premature failure due to mixture brittleness [17]. In this research, all asphalt mixtures measured flow values above the minimum $2.0 \mathrm{~mm}$ required and only two mixtures measured flow values above the maximum $4.0 \mathrm{~mm}$ specified limit following MoWT General Specifications for Road and Bridge Works of Uganda. Asphalt mixtures prepared with 5.3 and 5.7 percent filler content were above the maximum flow values at low bitumen content of 4.2 percent as presented in Figure 9. This means that the bitumen content added to the mixture was less to induce plastic flow in specimens. The little filler added into the mix increased the surface area and hence increase internal friction between aggregate particles. Generally, 10 percent of the mixtures achieved flow values above the allowable maximum limit of $4.0 \mathrm{~mm}$, while 90 percent of the flow values achieved lie within the required limits of 2 to $4 \mathrm{~mm}$ recommended.

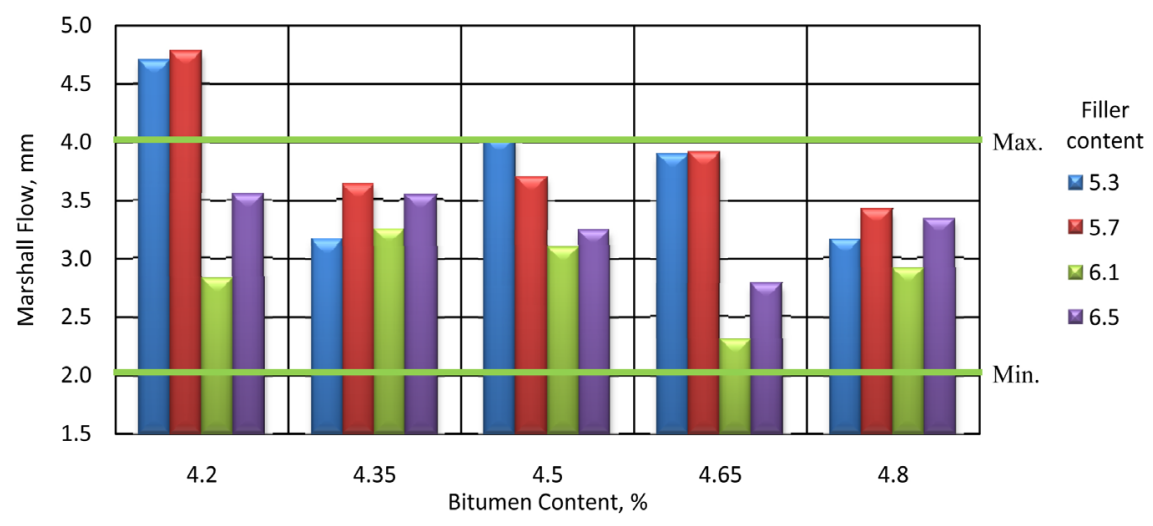

Figure 9. Variation of flow values with bitumen contents. 


\subsubsection{Effect on Bulk Density}

Bulk density of the compacted mix employing 75 blows on both sides, increases with increasing filler content up to a maximum then it decreases slightly, but with further addition of filler, bulk densities increased higher following the same trend in all mixes. This may be due to a decrease in voids in the mineral aggregates as filler content increases, hence increased bulk density presented in Figure 10. In the compacted mix, density is directly related to voids. The lowest bulk densities of the compacted specimens were observed in the mixtures containing 5.3 percent filler. At lower content the mix becomes stiffer hence requiring greater compaction effort and consequently lower dense mixtures obtained. This phenomenon was not experienced for the mixtures prepared with much more amount of filler. The highest bulk densities were observed in mixtures with 6.5 percent filler. Commonly, the more the filler quantity is added into the aggregate blend, the more the mixture can be easily compacted and hence higher compacted density. The reverse is true, the less the filler quantity is added, the less the mixture can be compacted and hence less compacted density is achieved. Filler reduces the air voids and increases the density of the compacted mixture. For each filler content, the higher the density of the mix, the lower the percentage of voids in the mix, and vice versa. This means that the densification of asphalt mixtures is influenced by filler content. The maximum bulk density achieved was $2.375 \mathrm{~g} / \mathrm{cc}$ for DBM mixtures with a filler/asphalt ratio of 1.4 at a proportion of asphalt content 4.65 percent. Yet, Sady A. Tayh [21] reported the maximum bulk density of $2.353 \mathrm{~g} / \mathrm{cc}$ for the asphalt mixture that was achieved after using a filler/binder ratio of 1.5 at a proportion of asphalt content 4.95 percent.

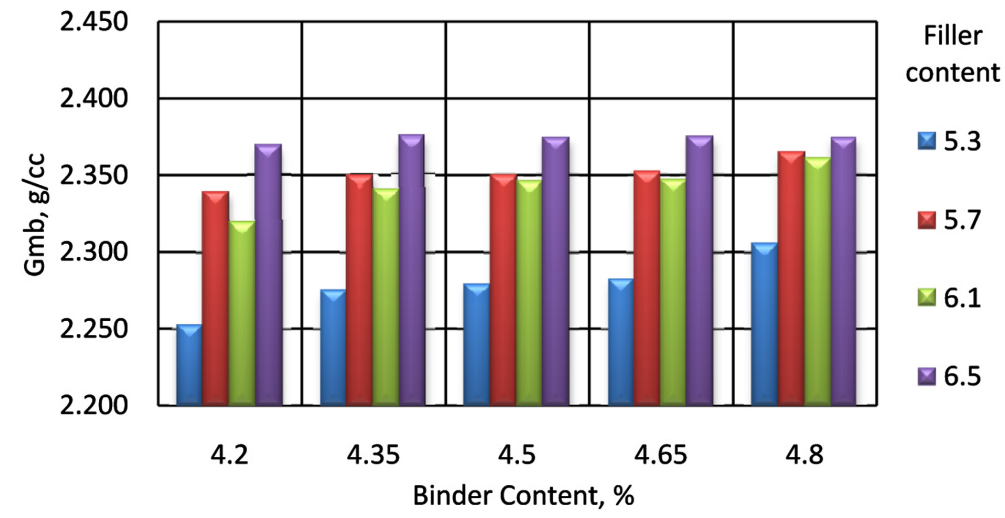

Figure 10. Bulk density of compacted mix vs. bitumen content.

\subsubsection{Effect on Air Voids (VA)}

Air voids are small spaces of air that occur between the coated aggregate particles in the final compacted mix. A certain percentage of air voids is essential in all asphalt pavement mixtures to allow some secondary compaction under traffic. Also, air voids in the compacted mixture provide spaces into which some 
small amounts of bitumen can flow during subsequent compaction. The durability of an asphalt pavement mixture is a function of air-voids content. This is because the lower the air-voids content, the less permeable the mixture becomes. Too high an air-voids content above 8.0 percent, provides passageways through the asphalt mixture for the ingress of destructive air and moisture. Too low of an air void content less than 3.0 percent can lead to bleeding, a condition in which excess bitumen squeezes out of the mix to the surface. For all filler contents in this research, air voids decreased with increasing filler and binder content. A higher amount of air voids ( $\geq 8.0$ percent) was measured in mixtures with the lowest percentage of filler content (5.3 percent), such mixtures with insufficient binder and high air voids are prone to ingress of air and water hence oxidation. The least amount of air voids ( $<3$ percent) was measured in mixtures with the highest percentage of filler content ( 6.5 percent). Generally, it was evident that 5 percent of the mixes achieved air voids less than 3.0 percent, 10 percent of the mixes achieved air voids content above 8.0 percent, while 85 percent of the mixes attained air voids between 3.0 and 8.0 percent as indicated in Figure 11. This justifies that using inert filler in preparation of bituminous mixtures makes the bitumen more solid and stiffer hence affect the air voids. As well, beyond a certain range of filler-to-binder ratio ( $0.8-1.6$ by mass) recommended by the Asphalt Institute in MS-2 for DBM mixtures, the values may not comply with the Ugandan specifications.

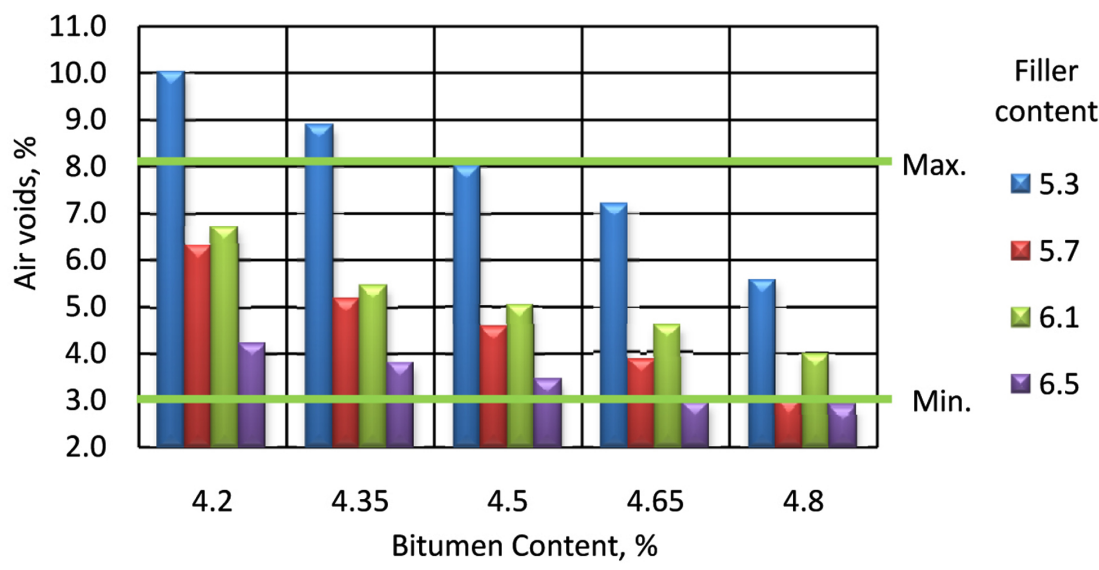

Figure 11. Relationship between bitumen content with air voids.

\subsubsection{Effect on Voids in Mineral Aggregate (VMA)}

Voids in mineral aggregate (VMA) are the air-void spaces that exist between the aggregate particles in a compacted mixture, including spaces filled with bitumen. The space available to accommodate bitumen and the voids necessary in the mixture is represented by VMA. The primary purpose of VMA is to ensure reasonably high bitumen content to coat the aggregate particles in the mix. An increase in the filler proportion, generally decreases the VMA but further increase beyond the maximum required in a mix increases the VMA with increasing bi- 
tumen content as shown in Figure 12. This is due to the relationship between particle diameter and surface area. Increasing the amount of material passing the $0.075 \mathrm{~mm}$ sieve, result in a larger overall surface area of the aggregate blend. Bruce A. et al. [22] in a report said that though there was increase in the fines of the asphalt after construction, a change in total surface area is not expected. That without particle diameter the contribution of the material passing $0.075 \mathrm{~mm}$ sieve, their surface area cannot be accurately estimated. It can be assumed that the larger this percentage is, the greater the actual surface area. All mixtures indicated satisfied the VMA minimum requirement of 12.5 percent following the Overseas Road Note 31 [23]. VMA decreases with increasing bitumen content in the mixture. The more VMA in the dry aggregate, the more space is available for bitumen film on the aggregate particles, the more durable the paving mixture. Minimum VMA values should be achieved for a durable asphalt film thickness. When the aggregate gradation is made denser, VMA values obtained lead to thinner asphalt film and a dry looking mix and hence a low durability mix.

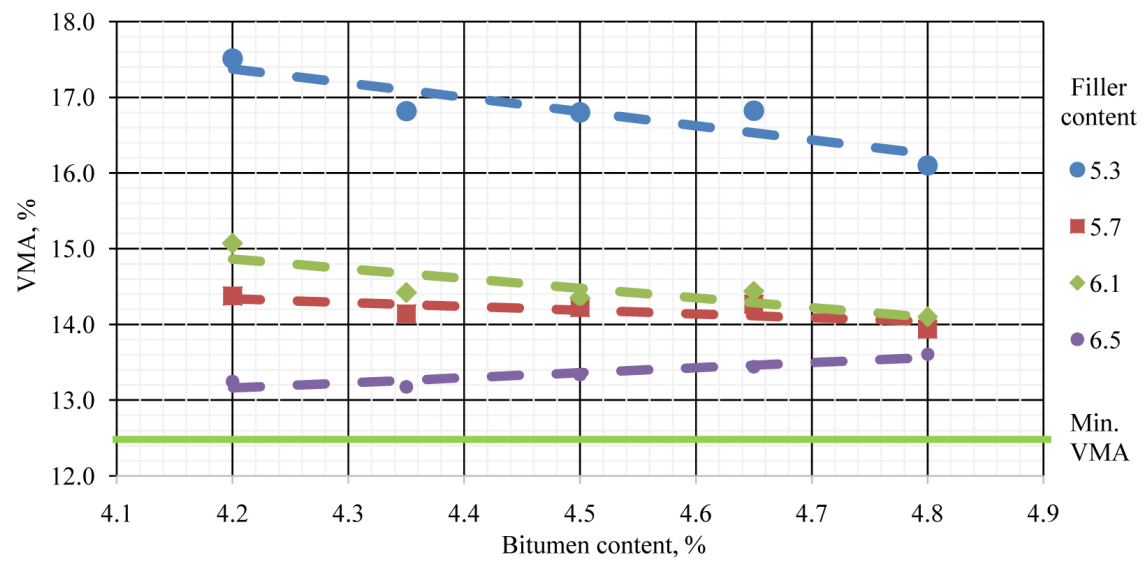

Figure 12. Relationship between bitumen content with VMA (\%).

\subsubsection{Effect on Voids Filled with Bitumen (VFB)}

DBM mixes should maintain a reasonable amount of air voids between $65-75$ percent expected to be filled with bitumen following the Marshall criteria which are important for the durability of mixes. If the percentage of voids filled with a binder is lower than the limit indicated in Figure 13, there will be less binder film around the aggregate particles. Lower binder films are more subjected to moisture and weather effects where they can be detached from the aggregate particles and subsequently lower performance. On the other hand, if the limit is exceeded, more voids are filled with binder than required for durability. This can be explained as the binder film around aggregate particles is thicker and lower voids than required are left. This increased amount of effective binder results in bleeding and lower stiffness of the mix. Mixtures prepared by 5.3 percent filler content for all binder contents, the voids filled with a binder is lower than the minimum limit set by Marshall criteria. This implied that the designed mixture 
had excessive voids to accommodate both filler and binder at the same time. In general, 40 percent of the mixes achieved VFB below the minimum 65 percent required, such mixes were observed to be drier and brittle. Then 45 percent of the mixes achieved VFB between 65 and 75 percent as required, while 15 percent of the mixes achieved VFB above the maximum 75 percent needed. Such mixtures having VFB above the maximum value 75 percent were tender and shiny and difficult to compact since they contained a higher percentage of bitumen and mineral filler.

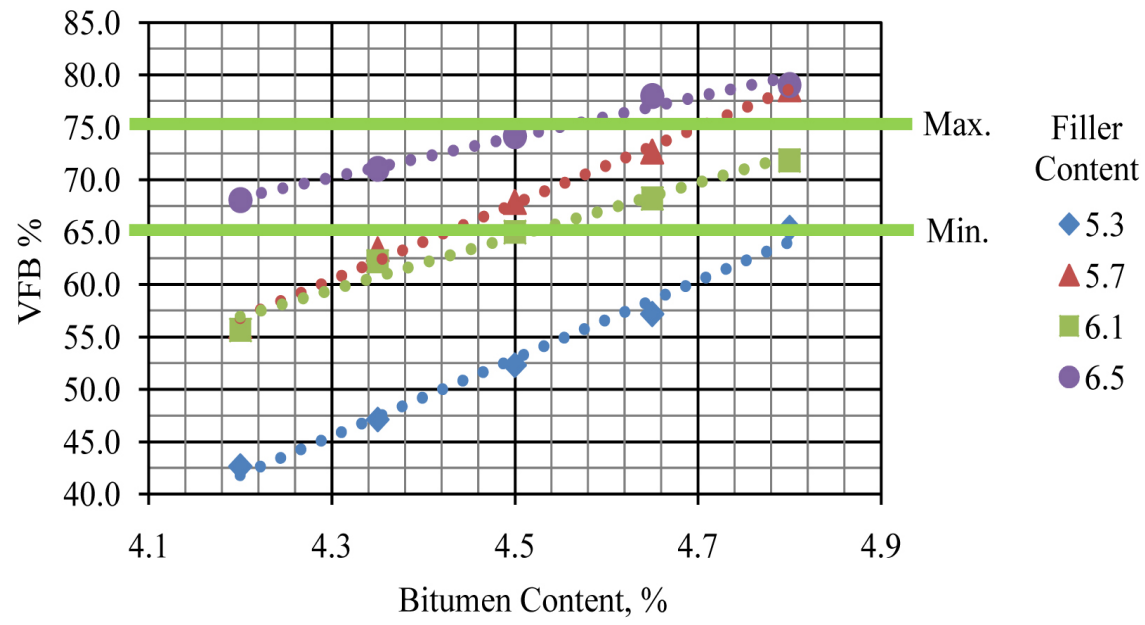

Figure 13. Relationship between bitumen content with VFB (\%).

\subsection{Refusal Density Compaction}

\subsubsection{Refusal Density Compaction by an Automatic Marshall Impact Hammer}

This is a procedure of extended Marshall compaction to design asphalts mixtures that can retain the required minimum voids in the mix after secondary compaction by traffic as highlighted by the Overseas Road Note 31 [23]. It is a continued Marshall compaction until no further densification of the mix is obtained. Durable mixes require a high degree of compaction and this is best achieved by compacting specimens to refusal density. Air voids were determined in the compacted specimens and those retained 3.0 percent and above were considered satisfactory. Those specimens which failed to achieve the minimum 3.0 percent were regarded as unsuitable for road pavement construction. The measured results shown in Table 13 were obtained after testing mixtures that contained filler and bitumen content varied from the optimum as earlier determined.

In all categories of filler content, air voids decreased with increasing bitumen content as presented in Figure 14. Also, air voids decreased with increasing filler content for all mixtures. DBM mixtures prepared with fewer filler content retained more air voids compared to those with more filler. Generally, 65 percent of the total mixes retained air voids above 3.0 percent minimum required, 15 
percent of the mixes retained air void above 2.5 percent, while 20 percent of the total mixes retained air voids below 2.5 percent. The more the filler is added into an asphalt mix, the less the air voids are retained in a compacted mix. Similarly, the more bitumen is added into an asphalt mix the less the retained air voids. The reverse is true the fewer the filler, the more the retained air voids in compacted specimens and the less the binder the more air voids left in a compacted specimen. Considering the analysis above, not all mixes prepared within the specified range of filler-to-binder ratio can retain the minimum air voids when compacted for PRD test using an automatic Marshall impact hammer. This is because the incorporation of filler in the aggregate blend, slightly shifts the gradation curve to the finer side and this changes the volumetric properties of the mixture. Mixtures with a slightly more amount of filler content tend to fill all the air spaces left in the fine aggregate and hence reduced air voids.

Table 13. Retained air voids in the mixture after 400 blows on each face.

\begin{tabular}{|c|c|c|c|c|c|c|}
\hline $\begin{array}{l}\text { Filler Content } \\
\text { of mix, } \mathrm{P}_{0.075}\end{array}$ & $\begin{array}{l}\text { Bitumen } \\
\text { Content of } \\
\text { mix, } \mathrm{Pb}\end{array}$ & $\begin{array}{c}\text { Dust to } \\
\text { binder ratio } \\
\mathrm{P}_{0.075} / \mathrm{Pb}\end{array}$ & $\begin{array}{c}\text { Bitumen } \\
\text { SG, Gb }\end{array}$ & $\begin{array}{c}\text { Maximum } \\
\text { SG, Gmm }\end{array}$ & $\begin{array}{l}\text { Bulk density } \\
\text { of compacted } \\
\text { mix, Gmb }\end{array}$ & $\begin{array}{c}\text { Air } \\
\text { voids, } \\
\text { VA }\end{array}$ \\
\hline (\%) & (\%) & & & & $(\mathrm{g} / \mathrm{cc})$ & (\%) \\
\hline 5.3 & 4.20 & 1.26 & 1.028 & 2.504 & 2.299 & 8.2 \\
\hline 5.3 & 4.35 & 1.22 & 1.028 & 2.497 & 2.289 & 8.3 \\
\hline 5.3 & 4.50 & 1.18 & 1.028 & 2.478 & 2.321 & 6.3 \\
\hline 5.3 & 4.65 & 1.14 & 1.028 & 2.459 & 2.347 & 4.6 \\
\hline 5.3 & 4.80 & 1.10 & 1.028 & 2.442 & 2.340 & 4.2 \\
\hline 5.7 & 4.20 & 1.36 & 1.028 & 2.496 & 2.394 & 4.1 \\
\hline 5.7 & 4.35 & 1.31 & 1.028 & 2.477 & 2.387 & 3.6 \\
\hline 5.7 & 4.50 & 1.27 & 1.028 & 2.462 & 2.382 & 3.3 \\
\hline 5.7 & 4.65 & 1.23 & 1.028 & 2.448 & 2.373 & 3.1 \\
\hline 5.7 & 4.80 & 1.19 & 1.028 & 2.438 & 2.367 & 2.9 \\
\hline 6.1 & 4.20 & 1.45 & 1.028 & 2.485 & 2.378 & 4.3 \\
\hline 6.1 & 4.35 & 1.40 & 1.028 & 2.475 & 2.379 & 3.9 \\
\hline 6.1 & 4.50 & 1.36 & 1.028 & 2.470 & 2.391 & 3.2 \\
\hline 6.1 & 4.65 & 1.31 & 1.028 & 2.460 & 2.384 & 3.1 \\
\hline 6.1 & 4.80 & 1.27 & 1.028 & 2.458 & 2.395 & 2.6 \\
\hline 6.5 & 4.20 & 1.55 & 1.028 & 2.474 & 2.405 & 2.8 \\
\hline 6.5 & 4.35 & 1.49 & 1.028 & 2.469 & 2.408 & 2.4 \\
\hline 6.5 & 4.50 & 1.44 & 1.028 & 2.459 & 2.419 & 1.6 \\
\hline 6.5 & 4.65 & 1.40 & 1.028 & 2.447 & 2.420 & 1.1 \\
\hline 6.5 & 4.80 & 1.35 & 1.028 & 2.444 & 2.423 & 0.9 \\
\hline
\end{tabular}




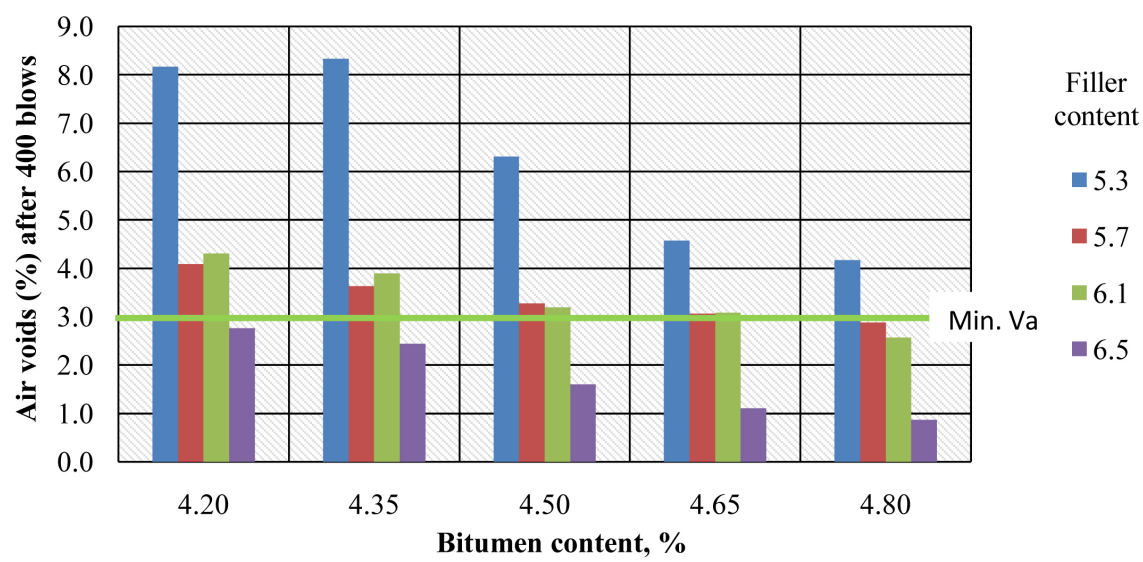

Figure 14. Relationship between bitumen content with air voids at refusal compaction 400 blows.

\subsubsection{Refusal Density Compaction by an Electrically Operated Vibrating Hammer}

This is an alternative method, based on the extended Marshall compaction procedure used in the PRD test [24], which uses a vibrating hammer for compaction. Mixtures were prepared and subjected to a 2-minute vibration on each face, using a vibrating hammer as a means of refusal compaction to determine retained air voids. The specimens were compacted in a $153 \mathrm{~mm}$ diameter mould to an approximate thickness to be laid on the road [23]. Table 14 shows test results from compacted specimens using a vibrating hammer tool, for mixtures designed with different filler and binder contents and later checked for retained air voids.

Table 14. Retained air voids in the mixture after using a vibrating hammer.

\begin{tabular}{ccccccc}
\hline $\begin{array}{c}\text { Dust Content } \\
\text { of mix, } \mathrm{P}_{0.075}\end{array}$ & $\begin{array}{c}\text { Bitumen } \\
\text { Content } \\
\text { of mix, Pb }\end{array}$ & $\begin{array}{c}\text { Dust to } \\
\text { binder ratio } \\
\mathrm{P}_{0.075} / \mathrm{Pb}\end{array}$ & $\begin{array}{c}\text { Bitumen } \\
\text { SG, Gb }\end{array}$ & $\begin{array}{c}\text { Maximum } \\
\text { SG, Gmm }\end{array}$ & $\begin{array}{c}\text { Bulk Density } \\
\text { of compacted } \\
\text { mix, Gmb }\end{array}$ & $\begin{array}{c}\text { Air } \\
\text { voids, } \\
\text { Va }\end{array}$ \\
\hline$\%$ & $\%$ & & & & $(\mathrm{~g} / \mathrm{cc})$ & $\%$ \\
\hline 5.3 & 4.20 & 1.26 & 1.028 & 2.504 & 2.329 & 7.0 \\
5.3 & 3.50 & 1.51 & 1.028 & 2.497 & 2.359 & 5.5 \\
5.3 & 4.50 & 1.18 & 1.028 & 2.478 & 2.397 & 3.3 \\
5.3 & 4.65 & 1.14 & 1.028 & 2.459 & 2.384 & 3.1 \\
5.3 & 4.80 & 1.10 & 1.028 & 2.442 & 2.370 & 2.9 \\
5.7 & 4.20 & 1.36 & 1.028 & 2.496 & 2.431 & 2.6 \\
5.7 & 4.35 & 1.31 & 1.028 & 2.477 & 2.430 & 1.9 \\
5.7 & 4.50 & 1.27 & 1.028 & 2.462 & 2.431 & 1.3 \\
5.7 & 4.65 & 1.23 & 1.028 & 2.448 & 2.429 & 0.8 \\
5.7 & 4.80 & 1.19 & 1.028 & 2.438 & 2.426 & 0.5 \\
6.1 & 4.20 & 1.45 & 1.028 & 2.485 & 2.395 & 3.6 \\
6.1 & 4.35 & 1.40 & 1.028 & 2.475 & 2.436 & 1.6 \\
\hline
\end{tabular}




\section{Continued}

\begin{tabular}{lllllll}
\hline 6.1 & 4.50 & 1.36 & 1.028 & 2.470 & 2.440 & 1.2 \\
6.1 & 4.65 & 1.31 & 1.028 & 2.460 & 2.446 & 0.6 \\
6.1 & 4.80 & 1.27 & 1.028 & 2.458 & 2.431 & 1.1 \\
6.5 & 4.20 & 1.55 & 1.028 & 2.474 & 2.442 & 1.3 \\
6.5 & 4.35 & 1.49 & 1.028 & 2.469 & 2.443 & 1.0 \\
6.5 & 4.50 & 1.44 & 1.028 & 2.459 & 2.435 & 0.9 \\
6.5 & 4.65 & 1.40 & 1.028 & 2.447 & 2.435 & 0.5 \\
6.5 & 4.80 & 1.35 & 1.028 & 2.444 & 2.438 & 0.2 \\
\hline
\end{tabular}

It was found out that only 25 percent of the mixtures could retain the required 3.0 percent air voids as the minimum recommended by the MoWT specification for Uganda. 10 percent of the mixtures had air voids above 2.5 percent which can be accepted when reported to one whole number and 65 percent retained air voids less than 2.5 percent. Almost all mixtures categorized with 5.3 percent filler content retained the required air voids except one with the highest binder content of 4.8 percent. One mixture under the grouped filler content of 6.1 percent measured air voids above 3.0 percent at a bitumen content of 4.2 percent which is less than the optimum binder content as shown in Figure 15. This indicates that air voids in an asphalt mixture are affected by both filler and bitumen contents. The more filler is added in an asphalt mixture, the less air voids retained and the reverse is true, the less filler added the more retained air voids. The same applies to binder content in the asphalt mixtures. Also, the delivered energy variables, the efficiency in energy transfer, and the difficulty to spot operation problems when using the vibrating hammer contribute much to further densification of mixtures, hence reduced air voids.

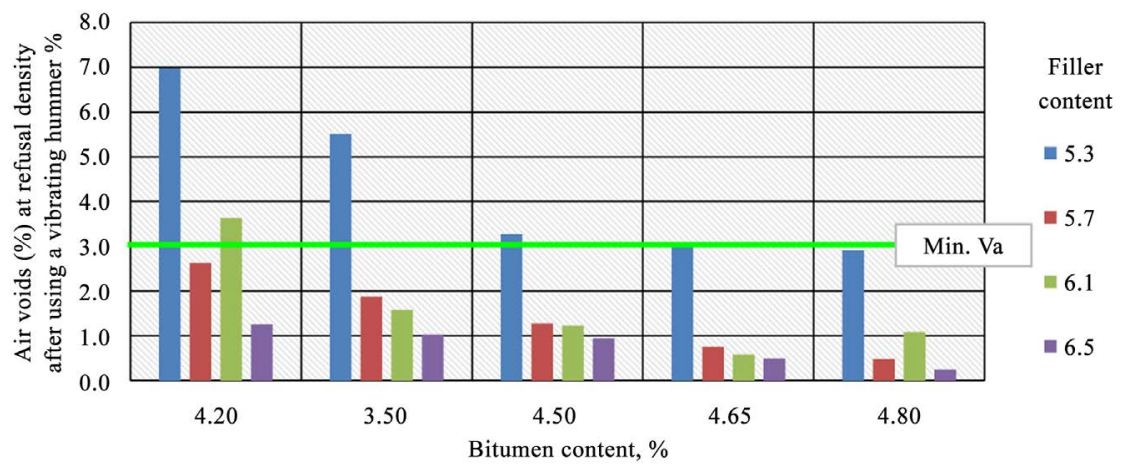

Figure 15. Relationship between bitumen content with air voids with a vibrating hammer.

\subsubsection{Refusal Density Compaction by a Gyratory Mechanism}

Among many testing tools for analyzing compaction characteristics of asphalt mixtures, a Superpave gyratory compactor was also used to simulate the compaction process of DBM mixtures. The aim was to find out whether DBM mix- 
tures designed using the Marshall method could retain the minimum air voids when compacted using 205 gyrations. According to Freddy et al. [25], the compaction device had been designed to compact hot-mix asphalt samples to a density similar to that obtained in the field under traffic. The gyratory compactor was used on DBM mixtures prepared in four major categories and test results are shown in Table 15.

Table 15. Retained air voids in the mix after using a gyratory compactor.

\begin{tabular}{ccccccc}
\hline $\begin{array}{c}\text { Dust Content } \\
\text { of mix, } \mathrm{P}_{0.075}\end{array}$ & $\begin{array}{c}\text { Bitumen } \\
\text { Content of } \\
\text { mix, Pb }\end{array}$ & $\begin{array}{c}\text { Dust to } \\
\text { binder ratio } \\
\mathrm{P}_{0.075} / \mathrm{Pb}\end{array}$ & $\begin{array}{c}\text { Bitumen } \\
\text { SG, Gb }\end{array}$ & $\begin{array}{c}\text { Maximum } \\
\text { SG, Gmm }\end{array}$ & $\begin{array}{c}\text { Bulk Density } \\
\text { of compacted } \\
\text { mix, Gmb }\end{array}$ & $\begin{array}{c}\text { Air } \\
\text { voids, } \\
\text { Va }\end{array}$ \\
\hline$(\%)$ & $(\%)$ & & & & $(\mathrm{g} / \mathrm{cc})$ & $(\%)$ \\
\hline 5.3 & 4.20 & 1.26 & 1.028 & 2.504 & 2.416 & 3.5 \\
5.3 & 3.50 & 1.51 & 1.028 & 2.497 & 2.433 & 2.6 \\
5.3 & 4.50 & 1.18 & 1.028 & 2.478 & 2.436 & 1.7 \\
5.3 & 4.65 & 1.14 & 1.028 & 2.459 & 2.437 & 0.9 \\
5.3 & 4.80 & 1.10 & 1.028 & 2.442 & 2.450 & 0.0 \\
5.7 & 4.20 & 1.36 & 1.028 & 2.496 & 2.430 & 2.6 \\
5.7 & 4.35 & 1.31 & 1.028 & 2.477 & 2.416 & 2.4 \\
5.7 & 4.50 & 1.27 & 1.028 & 2.462 & 2.445 & 0.7 \\
5.7 & 4.65 & 1.23 & 1.028 & 2.448 & 2.436 & 0.5 \\
5.7 & 4.80 & 1.19 & 1.028 & 2.438 & 2.447 & 0.0 \\
6.1 & 4.20 & 1.45 & 1.028 & 2.485 & 2.422 & 2.5 \\
6.1 & 4.35 & 1.40 & 1.028 & 2.475 & 2.415 & 2.4 \\
6.1 & 4.50 & 1.36 & 1.028 & 2.470 & 2.420 & 2.0 \\
6.1 & 4.65 & 1.31 & 1.028 & 2.460 & 2.437 & 1.0 \\
6.1 & 4.80 & 1.27 & 1.028 & 2.458 & 2.434 & 1.0 \\
6.5 & 4.20 & 1.55 & 1.028 & 2.474 & 2.417 & 2.3 \\
6.5 & 4.35 & 1.49 & 1.028 & 2.469 & 2.434 & 1.4 \\
6.5 & 4.50 & 1.44 & 1.028 & 2.459 & 2.437 & 0.9 \\
& 4.65 & 1.40 & 1.028 & 2.447 & 2.432 & 0.6 \\
6 & & 1.35 & 1.028 & 2.444 & 2.437 & 0.3 \\
\hline & & & & &
\end{tabular}

For each filler category, bitumen increased with decreasing percentage of air voids retained in the mixtures as shown in Figure 16. Similarly, filler content increased with decreasing percentage of retained air voids. It was found out that only the drier mixes retained some reasonable amount of air voids content. The driest mixture comprised 5.3 percent filler and 4.2 percent binder content. This is an indication that it is hard to compact the dry mixture to its fullest. The bitumen quantity was not enough to fully coat the aggregate in the mixture that is why compaction was difficult. In general, only 5.0 percent of the total mixes 
compacted using the gyratory compactor with 205 gyrations, retained air voids content above 3.0 percent. 15 percent of the mixtures retained air voids between 2.5 and 3.0 percent. 80 percent of the mixtures retained air voids below 2.5 percent air voids. Test results shown in Figure 16 indicate that mixtures designed using the Marshall method do not retain the minimum air voids when compacted using a gyratory compactor. In general, Superpave Gyratory Compactor achieved less air voids content of the Marshall mixes; this prevents additional compaction as a result of traffic loads.

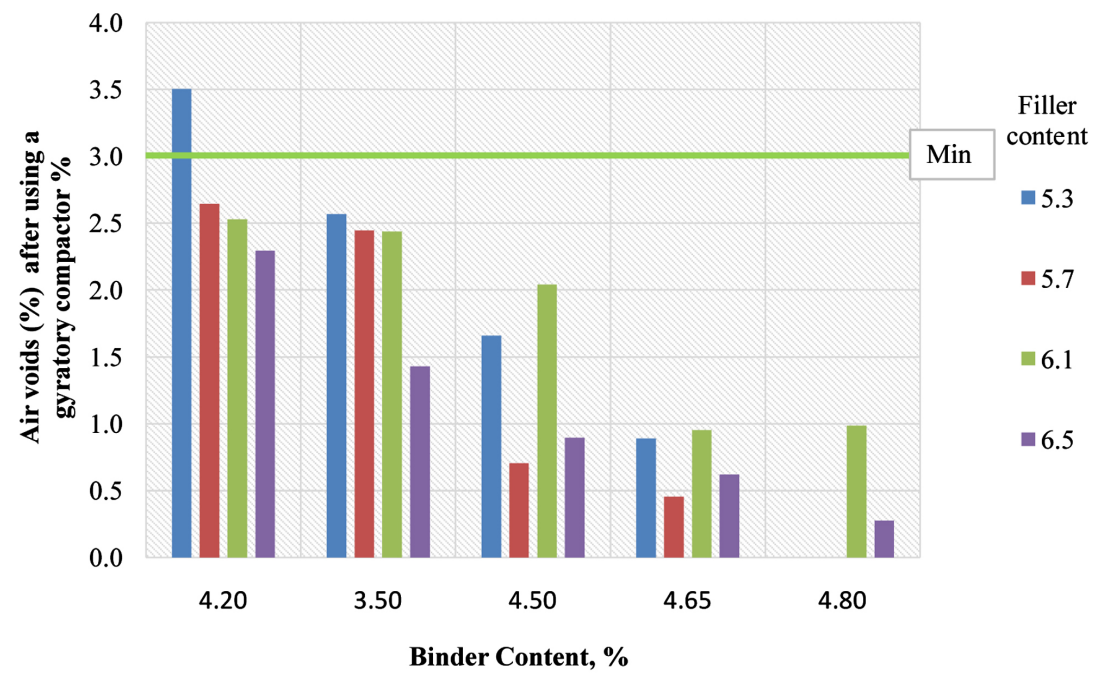

Figure 16. Relationship between bitumen content with Air voids after gyratory compaction.

In addition, choosing DBM mixtures prepared using the optimum filler content (5.7 percent), it suggests that it will take less energy to compact mixtures with less bitumen to achieve the required air voids than those with more bitumen. The same trend was observed with the compaction effort using a vibrating hammer and a gyratory compactor. This is clearly shown in the strong correlation obtained between bitumen content and retained air voids $\mathrm{R}^{2}=0.9557, \mathrm{R}^{2}=$ 0.9736 and $\mathrm{R}^{2}=0.9034$ in Figures 17-19 respectively. Air voids in the compacted mixtures seem to be more sensitive to the change in the bitumen content. This is illustrated by the coefficient of determination, $\mathrm{R}^{2}$.

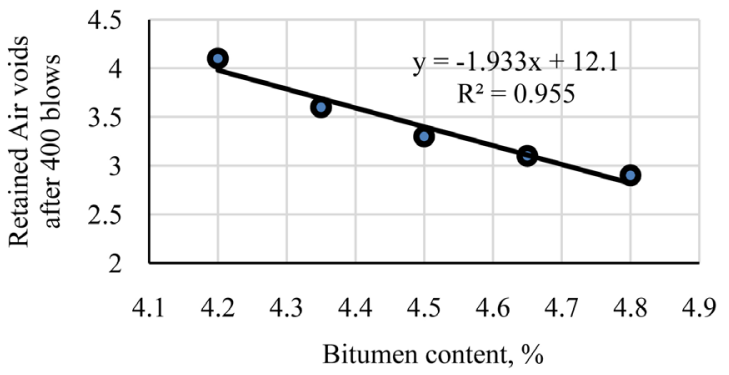

Figure 17. Impact hammer compaction. 


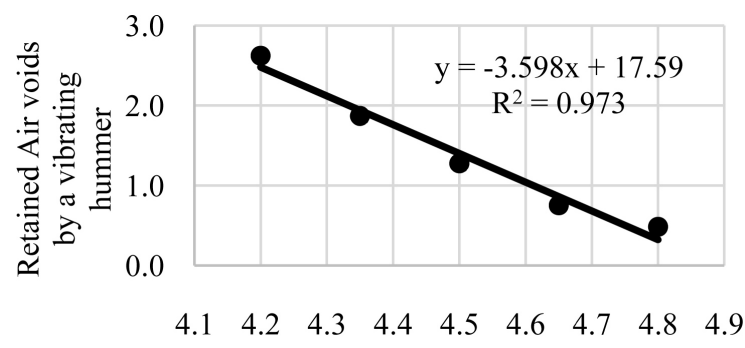

Bitumen Content, \%

Figure 18. Vibrating hammer compaction.

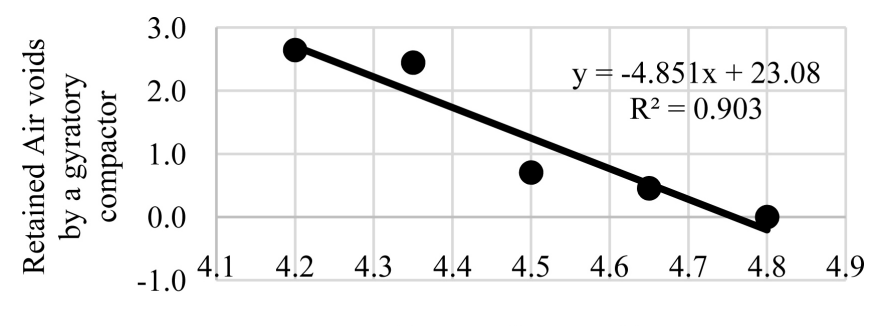

Bitumen Content, \%

Figure 19. Gyratory compaction.

\subsection{Comparison of Refusal Compaction Methods}

The Marshall compaction method, the vibrating hammer compaction method and the gyratory compaction method were used to investigate their impact when used to compact DBM mixtures. The compacted specimen prepared using the three tools mentioned above, were checked for retained air voids. The values achieved by the gyratory compaction method measured the highest impact. The method allowed almost no air voids in most mixtures of varying contents of filler and binder. It was followed by the vibrating hammer method where the compacted specimens retained almost similar results of retained air voids achieved after using a gyratory compactor. Lastly, the Marshall impact compaction method measured the least impact where almost all mixtures, apart from the one recorded with the highest filler content (6.5 percent) shown in Figure 20. The specimens produced using the Marshall impact compaction method has the best test accuracy as opposed to the vibrating hammer method and gyratory compaction mechanism. When the filler content remains fixed, the average air voids in compacted specimens are reduced with increasing binder content by at least 35 percent when the Marshall compactor was used, those compacted using a vibrating hammer air voids reduced by 75 percent, and those compacted using a gyratory compactor air voids reduced by 95 percent. Comparing the three compaction methods used in this research, if the designer is to choose either a vibrating hammer or a gyratory compactor to test specimens in a way of simulating secondary compaction by traffic, one is to design a mix with a fewer add-ons or without filler for better results. 


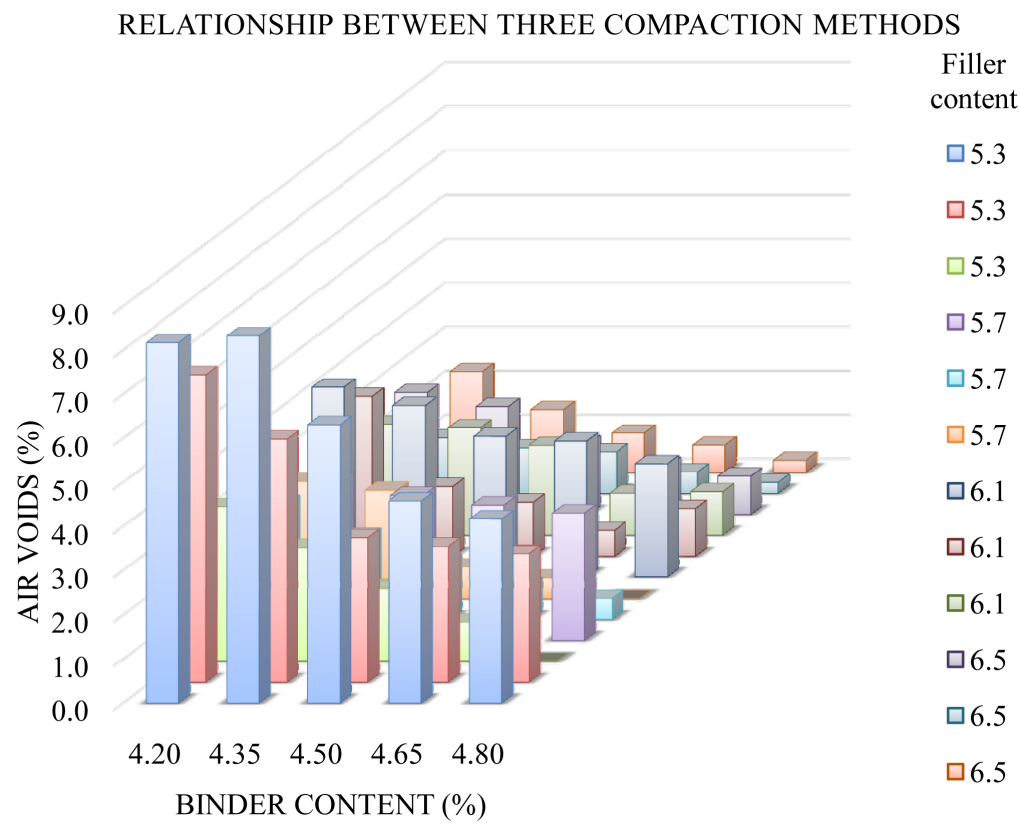

Figure 20. Relationship of three compaction methods.

\section{Conclusions and Recommendations}

\subsection{Conclusions}

The proportion of filler and binder contents in a bituminous mixture is critical and must be precisely determined at design. Therefore, the design mix formula developed in the laboratory should be treated as a guide in the mix design only, primarily used to estimate the contents of filler and binder close to optimum. The finer the mix gradation, the larger the total surface area of the aggregate and the greater the amount of bitumen required to uniformly coat the particles. Conversely, coarser mixes have a less total aggregate surface area, they demand less bitumen. The relationship between aggregate surface area and optimum binder content is most pronounced where filler material is involved.

Small increases in the amount of filler in a gradation can absorb much of the bitumen binder, resulting in a dry, unstable mix. Small decreases have the opposite effect i.e. too little filler results in the too rich mix. Variations in filler content cause changes in mix properties, from dry to wet. The relative proportions of the materials determine the physical properties of the mix, and ultimately, how the mix will perform as a finished pavement. Minor deviations in filler and/or binder content can usually be tolerated if the required volumetric properties are met. Mixtures with insufficient binder will always have higher air voids and such mixtures are brittle and such mixtures are prone to ingress of air and water hence oxidation.

For a selected gradation for any aggregate type, the filler content should be relative to the chosen compaction effort to be applied to compact specimens for the percentage refusal density test. When the contents of the DBM mixture had 
more mineral filler, it was easy to compact so an appropriate amount of mineral filler improves the workability of mixtures and contributes to compaction. Adding mineral filler to an asphalt mixture with more filler content beyond the maximum amount will not do good to compaction any longer; this is because excessive mineral filler will make mixtures dry and hard and do harm to compaction. When the content of coarse aggregate is kept constant, the mixture having more mineral filler and bitumen has a smaller air voids and density increase is attained. The asphalt mixture having enough fine aggregate but lacking enough mineral filler is more difficult to compact and the final air voids is high.

It is accepted that different laboratory asphalt compaction tools and methods produce samples with different retained air voids. The influence of the compaction method on the retained air voids of the mixes appeared to be mixture dependent. Even though the specimens prepared using an impact hammer yielded the best results, an electrically vibrating tool simulated more of the field compaction than the Marshall impact hammer tool and a gyratory compactor. Specimens prepared using an electrically operated vibrating tool for PRD test must have comparable thickness with the thickness to be laid on the road. When closely observed the operating mechanism of the electrically operated vibrating hammer tool when preparing DBM specimens, there was an element of impact and kneading at the same time. This is almost what happens in the field when compacting laid DBM mixtures whereby the initial compaction of the paved asphalt mixture is done using a steel double drum roller without vibration (kneading) and followed by two double drum roller passes with vibration (impact) and lastly with the dynamic rollers (kneading). Therefore, the best compaction method is an electrically vibrating hammer for mixtures designed using the Marshall method with precautions: 1) The gradation of the final aggregate blend should be closer to the coarser side of the gradation limits. 2) The filler content in the DBM mixture should be minimized in order to achieve the required air voids content.

\subsection{Recommendations}

1) Though in most cases, the optimum binder content is selected based on the compacted specimens having retained 4 percent air-voids, selection requires more of the engineering judgment, depending on traffic, climate and experience with the local materials used.

2) The results of this research work are thought to be used as the basis for further investigation on the effect of inert filler and binder contents to improve asphalt mixtures as well as find the best ranges.

3) The desired properties of any DBM mix should be checked and verified using the plant produced, laboratory compacted DBM mixture. Tests should be run to determine the characteristics of the mix being manufactured.

4) DBM mixtures designed following the Marshall criteria, will always be simulated for further densification by traffic using the extended Marshall method 
of compaction. The procedure helps the designer to closely compare the size of the specimens, visually tell the extent of coarse aggregate breakages if any. The sizes of the specimens prepared using an electrically vibrating hammer and a gyratory compactor, are not comparable. The specimens for both normal and extended Marshall test should be prepared at the same time to maintain similar conditions. Thus, the conditioning period and temperature regulation for DBM mixture to fabricate specimens should be similar in order to achieve comparable results. Since the specimens are small in size, the quartering of the DBM mixture should be carefully done to have specimens with balanced material.

\section{Conflicts of Interest}

The authors declare no conflicts of interest regarding the publication of this paper.

\section{References}

[1] Ganapati Naidu, P. and Adiseshu, S. (2013) Influence of Coarse Aggregates Shape Factors on Bituminous Mixtures. International Journal of Engineering Research and Application (IJERA), 1, 2013-2024.

[2] Garcia and Hansen (2001) Hot Mix Asphalt Pavement Mix Types and Selection Guide. National Pavement Association and Federal Highways Administration, Information Series, 4th Edition, Nairobi, 332-345.

[3] Kama, K.M. (2019) Specifications for Dense Bituminous Macadam and Bituminous Concrete for Airfield Pavement. Indian Roads Congress, 2-17.

[4] Ebrahim, S., Hasam, Z. and Maryam, S. (2015) The Effect of Aggregate Gradation Limits Consideration on Performance Properties and Mixture Design Parameters of Hot Mix Asphalt. KSCE Journal of Civil Engineering, 20, 385-392. https://doi.org/10.1007/s12205-015-0265-8

[5] Panda, R.P., Das, S.S. and Sahoo, P.K. (2017) Optimum Bitumen Content for Bituminous Concrete-An Alternative Approach for Estimation. International Journal of Civil Engineering and Technology, 8, 435-453.

[6] Stephen, J. (2001) Research Paper on Hot Mix Asphalt Mix Design Completed in Conjunction with Testing Lab Set-Up and Procedures. 2nd Edition, Southern Illinois University Edwardsville, Nairobi, 167-172.

[7] Lodhi, D.K.S. and Yadav, R.K. (2016) Effect of Gradation of Aggregates on Marshall Properties of SDBC Mix Design. International Journal of Engineering Research and Science and Technology, 5, 25-30. https://doi.org/10.15623/ijret.2016.0502005

[8] Cesare, T. and Ruggero, A. (2017) Adhesion Promoters in Bituminous Road Materials: A Review of Technology and Applications. Journal of Applied Science, Polarization Sensitive Optical Coherence Tomography, 7, 524. https://doi.org/10.3390/app7050474

[9] Scott, S. (2019) A Report on Improving Durability of Asphalt Mixtures, Applied Research and Innovation Branch. Department of Transportation Colorado, Federal Highway Administration. http:/www.codot.gov/programs/research

[10] Diab, A. and Enieb, M. (2017) Investigating Influence of Mineral Filler at Asphalt Mixture and Mastic Scales. International Journal of Pavement Research and Technology, 11, 213-224. https://doi.org/10.1016/j.ijprt.2017.10.008 
[11] Zaynab, I. (2017) Effect of Filler Content on Properties of Asphaltic Mixtures for Marshall and Superpave, Cape Town. Journal for Engineering and Science, 20, 183-193.

[12] Chu, V.T.H. (2011) A Self Learning Manual, Mastering Different Field of Civil Engineering Works (VC-Q-A-Method). 4th Edition, London, 333-345.

[13] American Association of State Highway and Transportation Officials (AASHTO T166) (2016) Method of Sampling and Testing, Bulk Specific Gravity of Compacted Bituminous Mixtures Using Saturated Surface-Dry Specimens. Washington DC.

[14] Asphalt Institute Manual Series No. 02 (2014) MS-2 Asphalt Mix Design Methods. 7th Edition, Library of Congress Control Number: 2014943435 USA.

[15] Ministry of Works and Transport, MoWT (2005) The Republic of Uganda General Specifications for Road and Bridge Works, Series 4000, Bituminous Base Coarse and Asphalt Concrete Surfacing. 9-23.

[16] American Association of State Highway and Transportation Officials (AASHTO T248) (2014) Standard Method of Test for Reducing Samples of Aggregate to Testing Size. New York, 142-149.

[17] Berhe Mehari, Z. (2007) Effect of Different Types of Filler Materials on Characteristics of Hot-Mix Asphalt Concrete. Thesis, School of Graduate Studies of Addis Ababa University, Addis Ababa, 334-356.

[18] Transport Research Laboratory (TRL) (2002) A Guide to the Design of Hot Mix Asphalt in Tropical and Sub-Tropical Countries. Overseas Road Note 19, TRL Limited, Berkshire.

[19] American Association of State Highway and Transportation Officials (AASHTO T 245) (2020) Standard Method of Test for Resistance to Plastic Flow of Bituminous Mixtures Using Marshall Apparatus.

[20] American Society for Testing and Materials (ASTM D242) (2019) Standard Specification for Mineral Filler for Asphalt Mixtures Pavements. ASTM International, West Conshohocken.

[21] Sady, A. and Tayh, H. (2013) The Effect of Filler/Asphalt Ratio on Voids in Mineral Aggregates and Asphalt Thickness in Hot Mix Asphalt. Journal of University of Babylon, 21, 1364-1376.

[22] Bruce, A., Eugene, L., Benita, L. and Samantha, S. (1999) A Research on the Effect of Voids in Mineral Aggregate (VMA) on Hot-Mix Asphalt Pavements. Minnesota Department of Transportation, St. Paul.

[23] Transport Research Laboratory (TRL) (1993) A Guide to the Structural Design of Bitumen-Surfaced Roads in Tropical and Sub-Tropical Counties. 4th Edition, Tokyo, 38.

[24] British Standard (BS 598-104) (1989) Sampling and Examination of Bituminous Mixtures for Roads and Other Paved Areas, Method of Test for the determination of Density and Compaction.

[25] Freddy, L. and Brown, E.R. (1996) Hot Mix Asphalt Materials, Mixture Design, and Construction. 3rd Edition, National Asphalt Pavement Association Research and Education Foundation, Tokyo, 44-49. 